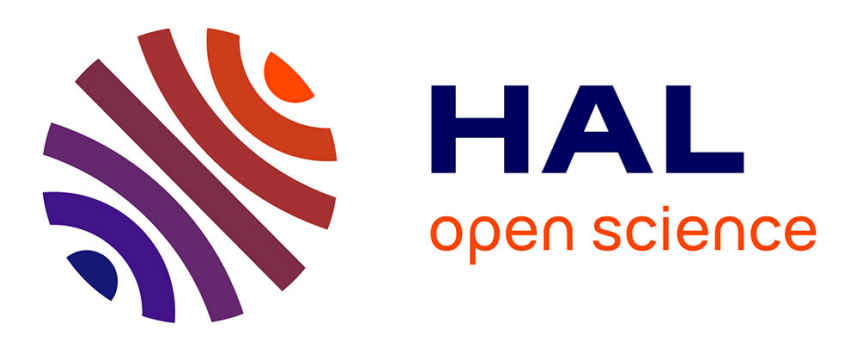

\title{
Influence of surface clinker on the crustal structures and dynamics of 'a'a lava flows
}

L.J. Applegarth, M.R. James, Benjamin van Wyk de Vries, H. Pinkerton

\section{To cite this version:}

L.J. Applegarth, M.R. James, Benjamin van Wyk de Vries, H. Pinkerton. Influence of surface clinker on the crustal structures and dynamics of 'a'a lava flows. Journal of Geophysical Research: Solid Earth, 2010, 115, pp.B07210. 10.1029/2009JB006965 . hal-00530994

\section{HAL Id: hal-00530994 \\ https://hal.science/hal-00530994}

Submitted on 27 Sep 2021

HAL is a multi-disciplinary open access archive for the deposit and dissemination of scientific research documents, whether they are published or not. The documents may come from teaching and research institutions in France or abroad, or from public or private research centers.
L'archive ouverte pluridisciplinaire HAL, est destinée au dépôt et à la diffusion de documents scientifiques de niveau recherche, publiés ou non, émanant des établissements d'enseignement et de recherche français ou étrangers, des laboratoires publics ou privés.

$$
\text { Copyright }
$$




\title{
Influence of surface clinker on the crustal structures and dynamics of 'a' $\mathbf{a}$ lava flows
}

\author{
L. J. Applegarth, ${ }^{1}$ M. R. James, ${ }^{1}$ B. van Wyk de Vries, ${ }^{2}$ and H. Pinkerton ${ }^{1}$ \\ Received 9 September 2009; revised 3 February 2010; accepted 23 March 2010; published 29 July 2010.
}

[1] Surface structures on 'a' $\bar{a}$ and blocky lavas reflect the internal flow dynamics during emplacement and also influence the dynamics of developing flows. To investigate the effects of brittle, clinkery 'a'ā flow crusts on flow dynamics and surface structures, we conducted sand and silicone laboratory experiments that simulated the advance of lava into a preexisting channelized flow with a surface crust. Experiments carried out with relatively thin crusts produced apparently ductile surface deformation structures, while thick crusts behaved dominantly in a brittle manner. Increased crustal thickness led to increased strength under compression but favored more disruption under tension, as the flow core welled up through tensile fractures, entraining crustal material. At lava flow fronts, upwelling and entrainment would increase heat losses by radiation and advection, respectively, resulting in a positive-feedback cooling loop. Fracturing caused heterogeneous crustal distribution near the flow front, which resulted in lobate flow advance, despite the absence of the viscoelastic layer that has previously been inferred as the primary control on flow advance and lobe formation. We therefore conclude that the influence of a purely brittle crust on the dynamics and surface morphologies of lava flows is more significant than often thought. All of the surface structures produced in the experiments have been observed on lavas or glaciers and many also on landslides and debris flows, suggesting the results can assist in the understanding of a range of natural flows.

Citation: Applegarth, L. J., M. R. James, B. van Wyk de Vries, and H. Pinkerton (2010), Influence of surface clinker on the crustal structures and dynamics of 'a'ā lava flows, J. Geophys. Res., 115, B07210, doi:10.1029/2009JB006965.

\section{Introduction}

[2] Lava flows demonstrate a wide range of behaviors, which depend on their intrinsic physical properties, the eruption conditions, and the environment into which they are erupted. Studying lava flow processes during emplacement is difficult because of the potential dangers of working near active flows and because the growth of a surface crust precludes direct observation of flow dynamics. Crustal growth strongly influences subsequent flow behavior. Crusts may either reduce cooling through insulation or enhance it through entrainment into the core [Crisp and Baloga, 1990] and can also modify flow advance, depending on their rheology. Rigid crusts force lava to advance as a series of breakouts, producing characteristic, crust-dominated, pāhoehoe morphology. In contrast, when the crust is highly fragmented, as in 'a'à basalts, advance occurs by the core-dominated "caterpillar-track" mechanism [Kilburn, 1993]. Interactions between crust and core result in the formation of branches and tubes, so are fundamental in flow field evolution [e.g., Greeley, 1987; Lipman and Banks, 1987; Kilburn and Lopes,

\footnotetext{
${ }^{1}$ Lancaster Environment Center, Lancaster University, Bailrigg, Lancaster, UK.

${ }^{2}$ Laboratoire Magmas et Volcans, Université Blaise Pascal, ClermontFerrand, France.

Copyright 2010 by the American Geophysical Union. 0148-0227/10/2009JB006965
}

1988, 1991; Fink and Griffiths, 1990]. Because the subsurface flow dynamics are reflected in crustal development, studying crustal evolution can provide insight into core motion and flow advance. Flow surface morphology can be used to constrain parameters including eruption rate, flow velocity, and local strain rate in unobserved flows [e.g., Gregg and Fink, 2000].

[3] Crust-core interactions are difficult to observe in the field and cannot currently be modeled numerically. Laboratory experiments provide an alternative method of studying lava flow behavior and have been employed by many authors using a variety of modeling substances with differing rheologies. The choice of material depends on the processes being investigated, as general lava flow evolution is strongly dependent upon the initial conditions. For example, Hawaiian lavas erupt at high temperatures and low crystallinities (e.g., $1140^{\circ} \mathrm{C}$ and $0.5 \%$, Mauna Loa, 1984) [Lipman and Banks, 1987] so their rheologies are initially close to Newtonian. Their development is largely controlled by rapidly increasing core crystallinities and the consequent dramatic changes in bulk rheology. In contrast, lavas on Mount Etna, Sicily, erupt at lower temperatures and higher crystallinities (e.g., $1086^{\circ} \mathrm{C}$ and 30\%-60\%, 1975 eruption) [Pinkerton and Sparks, 1978; Tanguy, 1973], so they already have a significant yield strength. Their emplacement is largely governed by crustal growth.

[4] Modeling approaches using cooling fluids that develop solid crusts, such as polyethylene glycol (PEG) wax [e.g., Greeley and Womer, 1981; Hallworth et al., 1987; Fink and 


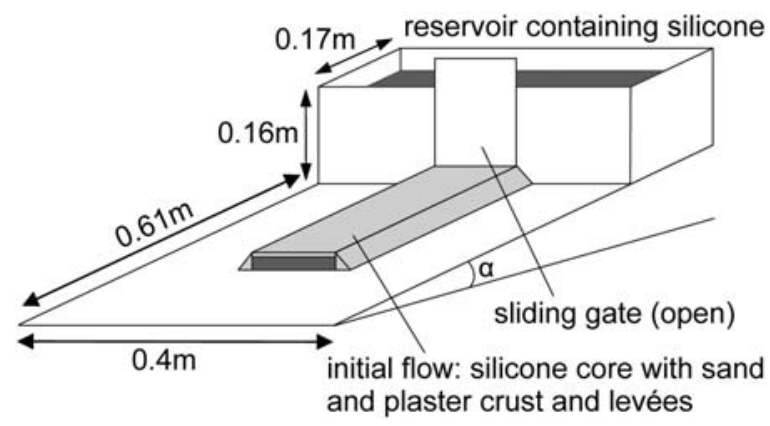

Figure 1. The experimental apparatus, showing the initial configuration of a flow. Dark gray shading indicates the silicone, and light gray indicates the sand and plaster. Elevating the reservoir end of the board changed the slope $\alpha\left(\prod_{3}\right)$.

Griffiths, 1990, 1992; Blake and Bruno, 2000; Gregg and Fink, 1995, 2000; Griffiths et al., 2003; Cashman et al. 2006; Lyman and Kerr, 2006] simulate bulk rheological changes, so are well suited to the study of Hawaiian-style flows. PEG crusts scale most appropriately to continuous pāhoehoe rather than fragmented 'a' $\bar{a}$ crusts because they are thin in comparison to the flow thickness, and their scaled strength is greater than lava crust strength [Fink and Griffiths, 1990; Soule and Cashman, 2004].

[5] Isothermal modeling approaches [e.g., Hulme, 1974; Huppert et al., 1982; Blake, 1990; Merle, 1998; Buisson and Merle, 2005; Lescinsky and Merle, 2005; Balmforth et al., 2006] face the problem of adequately simulating solidification. This may be addressed by using yield strength fluids [e.g., Hulme, 1974; Blake, 1990] or by combining modeling substances to produce a rheological stratification [e.g., Lescinsky and Merle, 2005]. The latter approach assumes that the rheological contrast between the hottest (core) and coolest (surface) end members is the most important factor governing flow behavior and that layers of intermediate temperature and rheology do not significantly influence the system, though field observations of pāhoehoe lavas have been used to suggest that an intermediate viscoelastic layer is of importance [Hon et al., 1994]. Models of this nature may be used to study Etnean-type flows, in which development is dominated by crustal growth.

[6] Here we build on the experiments of Lescinsky and Merle [2005] who used viscous silicone with a range of surface crust rheologies, subjected to a range of flow conditions, to examine strain partitioning and surface fracturing in channelized lava flows. Our work extends their study of brittle crust surface morphologies and also investigates the influence of crustal thickness and basal slope on the advance mechanisms of channelized flows. We aim to evaluate the relative contributions of crust and core to flow behavior and advance by examining the developing surface structures. By reproducing morphologies that are found on lava flows, the experiments may be used to interpret crustal structures in terms of internal flow dynamics and crust-core interaction.

\section{Experimental Methodology}

\subsection{Design}

[7] Our experiments simulated the advance of lava into a channel already containing a flow with or without a brittle crust. The use of channelized geometry follows the study of Merle [1998] and Lescinsky and Merle [2005], but there are important differences in our experimental design. The earlier work examined strain partitioning during spreading, therefore lubricated sidewalls were used to eliminate lateral shear in the majority of experiments, and no new material was introduced into any of the experiments. Because our aim was to reproduce the shear and velocity conditions experienced by channelized lava flows as closely as possible, we continually introduced fluid into the experimental channel, which was defined by sand levées.

[8] Lescinsky and Merle [2005] varied crustal thickness and slope in their brittle crust experiments, but the overlap in conditions between their models and ours is minimal. The introduction of material into our experimental channels resulted in different stress-strain distributions, allowing the examination of a wider range of crustal structures. The range of crustal thicknesses used is similar, but we studied a wider range of basal slopes $\left(4^{\circ}-12^{\circ}\right.$ compared to $\left.5^{\circ}-6^{\circ}\right)$. Gregg and Fink $[1995,2000]$ found that slope significantly modified morphological flow regimes identified in PEG flow models by Fink and Griffiths [1990, 1992].

[9] The problem of crustal thickening was addressed by the use of a range of crustal thicknesses, simulating lavas at various stages of emplacement. No single experiment was therefore intended to represent the full development of a lava flow. The unchanging rheology also prevented the downslope propagation of the levées during an experiment, but because of our interest in flow advance mechanisms, spreading beyond the levées was desirable.

\subsection{Materials}

[10] The flow core was simulated by a high viscosity $\left(10^{4} \mathrm{~Pa}\right.$ s) silicone fluid with Newtonian rheology. Although lavas demonstrate pseudoplastic, not Newtonian, rheology below their liquidus [Shaw, 1969; Pinkerton and Sparks, 1978], pseudoplastic rheology can be approximated by a Bingham model over a small range of strain rates. In turn, the behavior of a Newtonian fluid may approximate that of a Bingham fluid when its yield stress is exceeded. Models incorporating any of these rheologies may therefore provide useful insights into flow behavior, if scaled.

[11] The experimental crusts consisted of a dry mixture of quartz sand (negligible cohesion) [Mourgues and Cobbold, 2003] and plaster of Paris (cohesion of a few hundred Pascals) [Donnadieu and Merle, 1998], which has been found to successfully simulate the behavior of cohesive brittle clinker [Lescinsky and Merle, 2005].

\subsection{Method}

[12] Our apparatus consisted of a fluid reservoir with a sliding gate mounted at the end of a smooth, flat board (Figure 1). The reservoir end of the board was elevated to provide a down-flow slope, and an initial channelized flow was constructed adjacent to the gate, bounded laterally by sand levées. The initial flow comprised a silicone sheet (350 $\times$ $127 \times 15 \mathrm{~mm}$ ), representing the flow core, overlain by a dry mix of sand and plaster, the brittle crust. A volumetric sand to plaster ratio of 9:1 was used in four trial experiments (2-5), but thereafter, a ratio of 4:1 was found to improve the clarity of structures by damping collapse around their edges. The silicone sheet was prepared several hours before an experi- 
Table 1. Experimental Conditions

\begin{tabular}{|c|c|c|c|c|}
\hline Experiment & $T(\mathrm{~mm})$ & $\prod_{1}$ & $\prod_{3}$ & Duration of Experiment (h) \\
\hline 2 & - & - & 4 & 8.16 \\
\hline 3 & - & - & 4 & 6.22 \\
\hline 4 & 6 & 0.29 & 4 & 8.48 \\
\hline 5 & 9 & 0.38 & 4 & 7.71 \\
\hline 6 & 12 & 0.44 & 4 & 9.20 \\
\hline 7 & 6 & 0.29 & 8 & 9.30 \\
\hline 8 & 12 & 0.44 & 8 & 9.25 \\
\hline 9 & 3 & 0.17 & 4 & 11.6 \\
\hline 10 & 3 & 0.17 & 12 & 9.12 \\
\hline 11 & 3 & 0.17 & 8 & 9.37 \\
\hline 12 & 6 & 0.29 & 12 & 8.51 \\
\hline 13 & 15 & 0.50 & 8 & 8.51 \\
\hline 14 & 9 & 0.38 & 8 & 10.1 \\
\hline 15 & 3 & 0.17 & 8 & 7.23 \\
\hline 16 & 6 & 0.29 & 8 & 10.2 \\
\hline 17 & 6 & 0.29 & 4 & 10.9 \\
\hline 18 & 9 & 0.38 & 4 & 10.2 \\
\hline 19 & 3 & 0.17 & 4 & 9.32 \\
\hline 20 & 15 & 0.50 & 4 & 9.11 \\
\hline 21 & 6 & 0.29 & 4 & 9.22 \\
\hline 22 & 12 & 0.44 & 4 & 8.98 \\
\hline 23 & 9 & 0.38 & 12 & 7.44 \\
\hline 24 & 1 & 0.06 & 4 & 9.19 \\
\hline 25 & 0 & 0 & 4 & 10.7 \\
\hline 26 & 12 & 0.44 & 4 & 5.12 \\
\hline 27 & 12 & 0.44 & 4 & 11.1 \\
\hline 28 & 6 & 0.29 & 4 & 11.0 \\
\hline 29 & 3 & 0.17 & 4 & 10.2 \\
\hline 30 & 0 & 0 & 4 & 13.2 \\
\hline 31 & 3 & 0.17 & 4 & 11.3 \\
\hline 32 & 6 & 0.29 & 4 & 9.10 \\
\hline 33 & 9 & 0.38 & 4 & 12.6 \\
\hline 34 & 3 & 0.17 & 4 & 8.77 \\
\hline 35 & 12 & 0.44 & 4 & 13.7 \\
\hline 36 & 9 & 0.38 & 4 & 10.6 \\
\hline 37 & 12 & 0.44 & 4 & 11.7 \\
\hline 38 & 3 & 0.17 & 4 & 7.87 \\
\hline 39 & 6 & 0.29 & 4 & 13.9 \\
\hline
\end{tabular}

ment, then left to rest, allowing the escape of any air bubbles. To start an experiment, the reservoir gate was raised $15 \mathrm{~mm}$, and the sheet placed on the board with the upslope end in contact with the reservoir silicone exposed below the gate.
The crust was added by sieving through a $400 \mu \mathrm{m}$ mesh until the required depth was achieved. During sieving, point measurements of crustal depth (accurate to $\pm 0.5 \mathrm{~mm}$ ) were taken using a wire probe to ensure as even a thickness as possible. Crustal thickness was not monitored during the experiments because the complexity of crustal redistribution prevented characterization using point measurements and because the invasive measuring procedure may have induced weaknesses that were exploited as failure sites. Initial crustal thicknesses of 0 to $15 \mathrm{~mm}$ and slopes of $4^{\circ}$ to $12^{\circ}$ were used.

[13] After construction of the initial flow, black markers for tracking deformation (either carbide grains or mustard seeds) were scattered over the flow surface, and the experiment was left to proceed. Although construction of the initial flow took 5-10 min, no appreciable movement of the flow occurred during this time. As the flow advanced downslope over time, it was gravity fed at the head of the preformed channel by reservoir silicone flowing under the partially open lock gate. Experimental duration, limited by the length of the board, ranged from 5-14 h. After an experiment, internal flow structures were examined by removing the crustal material using a soft brush to reveal the silicone core.

[14] Each experiment was recorded using time-lapse digital photography. The image sequences allowed both the description of surface morphological changes and quantitative monitoring of crustal deformation through the tracking of the markers, using a correlation-based feature tracking procedure written in Matlab. Experimental conditions are listed in Table 1.

\subsection{Dimensional Analysis}

[15] To demonstrate similarity between the experiments and lava flows, we use a dimensional analysis similar to that of Lescinsky and Merle [2005]. The system is described by 11 independent variables with three dimensions (Table 2) which, according to $\prod$ theory, can be combined into eight dimensionless parameters, $\prod_{1-8}$. With $T$ as the crustal thickness; $F$ as the silicone thickness; $D$ as the total flow depth; $W$ as the flow width; $\alpha$ as the slope (believed to scale 1:1 with nature) [Gregg and Fink, 2000], $\rho_{c}$ and $\rho_{f}$ as the crust and core

Table 2. Variables Describing the Experimental and Lava Flow Systems

\begin{tabular}{|c|c|c|c|c|c|c|}
\hline & \multirow[b]{2}{*}{ Variable } & \multirow[b]{2}{*}{ Units } & \multirow[b]{2}{*}{ Dimensions } & \multicolumn{3}{|c|}{ Typical Values or Ranges } \\
\hline & & & & Basalt & Rhyolite & Experiment \\
\hline$D$ & total flow depth & $\mathrm{m}$ & $\mathrm{L}$ & $10^{0}-10^{1}$ a & $10^{1}-10^{2}$ a & $10^{-2}$ \\
\hline$T$ & crust thickness & $\mathrm{m}$ & $\mathrm{L}$ & $10^{-2}-10^{0}$ & $10^{0}-10^{1}$ & $10^{-3}-10^{-2}$ \\
\hline$W$ & flow width & $\mathrm{m}$ & $\mathrm{L}$ & $10^{0}-10^{2}$ & $10^{1}-10^{2}$ & $10^{-1}$ \\
\hline$\alpha$ & basal slope $\mathrm{b}^{\mathrm{b}}$ & $\left({ }^{\circ}\right)$ & - & $\ll 1->35$ & $\ll 1->35$ & $4,8,12$ \\
\hline$\rho_{f}$ & density of fluid & $\mathrm{kg} \mathrm{m}^{-3}$ & $\mathrm{M} \mathrm{L}^{-3}$ & $2700^{\mathrm{a}}$ & $2200^{\mathrm{a}}$ & 1400 \\
\hline$\rho_{c}$ & density of crust & $\mathrm{kg} \mathrm{m}^{-3}$ & $\mathrm{M} \mathrm{L}^{-3}$ & $2200^{\mathrm{c}}$ & $1800^{\mathrm{c}}$ & 1400 \\
\hline$\mu$ & initial viscosity of fluid & $\mathrm{Pa} \mathrm{s}$ & $\mathrm{M} \mathrm{L}^{-1} \mathrm{~T}^{-1}$ & $10^{2}-10^{4 d}$ & $10^{5}-10^{10 \mathrm{~d}}$ & $10^{4}$ \\
\hline$c$ & cohesion of crust & $\mathrm{Pa}$ & $\mathrm{M} \mathrm{L}^{-1} \mathrm{~T}^{-2}$ & $10^{4}-10^{6} \mathrm{e}$ & $10^{5}-10^{6} \mathrm{e}$ & $10^{2}$ \\
\hline$g$ & gravitational acceleration & $\mathrm{m} \mathrm{s}^{-2}$ & $\mathrm{~L} \mathrm{~T}^{-2}$ & 9.8 & 9.8 & 9.8 \\
\hline$t$ & emplacement time & $\mathrm{s}$ & $\mathrm{T}$ & $10^{-3}-10^{-2}$ & $10^{-1}-10^{4}$ & $10^{4}$ \\
\hline$\varphi$ & angle of internal friction & $\left({ }^{\circ}\right)$ & - & 30 & 30 & 30 \\
\hline
\end{tabular}

${ }^{\mathrm{a}}$ Kilburn [2000].

${ }^{\mathrm{b}}$ Slope can also be characterized as $H / B$, where $H$ is the height to the base of the reservoir, and $B$ is the length of the board, to give $\alpha=\tan (H / B)$. Here we use $\alpha$ because is it more easily understandable in field applications.

${ }^{\mathrm{c} C}$ Calculated from fluid density, with $20 \%$ vesicles.

${ }^{\mathrm{d}}$ At atmospheric pressure for volatile contents of $0-3 \mathrm{wt} \%$. Values for ranges of possible eruption temperatures: basalts at $1080^{\circ} \mathrm{C}-1400^{\circ} \mathrm{C}$; rhyolites at $800^{\circ} \mathrm{C}-1000^{\circ} \mathrm{C}$ [e.g., Friedman et al., 1963; Shaw et al., 1968; Shaw, 1972; Pinkerton and Sparks, 1978; Hess and Dingwell, 1996].

${ }^{\mathrm{e}}$ Cohesion of massive rocks $\sim 10^{7} \mathrm{~Pa}$ [Handin, 1966; Hoek et al., 1995] but that of fractured rock is one or two orders of magnitude less [Buisson and Merle, 2005], in agreement with heating experiments of Vesuvian basalt [Rocchi et al., 2004]. 
Table 3. Approximate $\prod$ Values in Lava Flows Compared With Those of the Experiments ${ }^{\mathrm{a}}$

\begin{tabular}{|c|c|c|c|c|c|}
\hline & & & \multicolumn{3}{|c|}{ Typical Values or Ranges } \\
\hline \multicolumn{3}{|c|}{ Dimensionless Parameters } & Basalt & Rhyolite & Experiment \\
\hline$\prod_{1}$ & crust/total flow thickness & $T / D$ & $10^{-2}-10^{-1}$ & $10^{-1}$ & $10^{-2}-10^{-1}$ \\
\hline$\prod_{2}$ & inverse aspect ratio & $W / D$ & $10^{0}-10^{-2}$ & $10^{1}$ & $10^{0}$ \\
\hline$\prod_{3}$ & crust/fluid density & $\rho_{c} / \rho_{f}$ & $10^{0}$ & $10^{0}$ & $10^{0}$ \\
\hline$\prod_{4}$ & slope & $\alpha$ & $\ll 1->35$ & $\ll 1->35$ & $4-12$ \\
\hline$\prod_{5}^{114}$ & gravitational/viscous forces & $\left(F \rho_{f}+T \rho_{c}\right) g t / \mu$ & $10^{2}-10^{10}$ & $10^{-1}-10^{6}$ & $10^{2}-10^{3}$ \\
\hline$\prod_{6}$ & cohesive/viscous forces & $\mathrm{Ct} / \mu$ & $10^{4}-10^{9}$ & $10^{0}-10^{7}$ & $10^{2}$ \\
\hline$\prod_{7}$ & inertial/viscous forces & $\rho_{f} D^{2} / \mu t$ & $10^{-9}-10^{-2}$ & $10^{-10}-10^{-3}$ & $10^{-9}-10^{-10}$ \\
\hline$\prod_{8}$ & frictional/viscous forces & $\rho_{c} g T t \tan \varphi / \mu$ & $10^{2}-10^{8}$ & $10^{-1}-10^{8}$ & $10^{1}-10^{2}$ \\
\hline
\end{tabular}

${ }^{a}$ Ranges of values reflect ranges in Table 2 and also values of the viscosity up to 3 orders of magnitude greater than those quoted in Table 2 , which only considered eruption viscosity.

densities, respectively; $g$ as the gravitational acceleration; $t$ as the emplacement time; $\mu$ as the silicone viscosity; $c$ as the crust cohesion; and $\varphi$ as the angle of internal friction of the crust, these parameters are

$\prod_{1}=$ crustal thickness $/$ total flow thickness $=T / D$

$\prod_{2}=$ flow width/total flow thickness $=W / D$

$\prod_{3}=$ slope $=\alpha$

$\prod_{4}=$ crust density/fluid density $=\rho_{c} / \rho_{f}$

$\prod_{5}=$ gravitational forces $/$ viscous forces $=g t D \rho_{f} / \mu$ or $\left(F \rho_{f}+T \rho_{c}\right) g t / \mu$

If flow occurs on a slope, $\prod_{5}$ needs to be multiplied by the sine of the slope $\prod_{3}$.

$\prod_{6}=$ cohesive forces/viscous forces $=c t / \mu$

$\prod_{7}=$ inertial forces $/$ viscous forces $=$ Reynolds number $=$ $\rho_{f} D^{2} / \mu t$

$\prod_{8}=$ frictional forces $/$ viscous forces $=\rho_{c} g T t \tan \varphi / \mu$

Certain of the above parameters can be written differently if a length scale $L$ and velocity $U$ are substituted for time $t: t=$ $L / U, \prod_{5}$ and $\prod_{7}$ then become

$\prod_{5}=g L^{2} \rho / \mu U$

$\prod_{7}=\rho L U / \mu$

[16] The ranges of values of the dimensionless parameters for basaltic and rhyolitic lava flows compare favorably with those for our experimental flows (Table 3), suggesting that our flows are applicable to lava flows within this compositional range.

\section{Results}

[17] General flow development was similar for all experiments, but the occurrence and appearance of surface structures varied with the initial ratio of crust to total flow thickness $\prod_{1}$ and slope $\prod_{3}$. The structures depended strongly on $\prod_{1}$ but only weakly on $\prod_{3}$ and included fractures (near the flow front and down the channel margins), ridges (near the head of the channel), and flow front lobes. The experiments are divided into four classes depending on the observed structures. These are "no" to "very thin" crusts: $\prod_{1} \leq 0.1$, "thin" crusts: $0.1<\prod_{1} \leq 0.2$, "intermediate" crusts: $0.2<\prod_{1}$ $\leq 0.3$ and "thick" crusts: $\prod_{1}>0.3$. The typical development of a thin and a thick crust experiment are shown in Figure 2.

[18] At the start of an experiment, the flow front sagged and rolled forward under gravity. In all but the "no/very thin" crust models, this caused tensile fractures to open in the surface crust behind the flow front (Figures 2a and 2e). Extension was observed at the flow front in the no/very thin crust models from relative motion of the surface markers. Flow front velocities were highest during this initial period
(Figure 3) before gradually decaying because of frontal thinning and, later, lateral spreading beyond the levées (Figures $2 \mathrm{~b}$ and $2 \mathrm{f}$ ).

[19] Flow fronts advanced by a caterpillar track mechanism. The upper, higher velocity part of the flow cascaded down at the front, depositing crustal material that was then overrun, resulting in a basal sand layer analogous to the basal breccia observed in 'a' $\bar{a}$ basalt and higher-silica flows. In flows with no crusts $\left(\prod_{1}=0\right)$, rollover at the flow front was evidenced by the overrunning of marker points.

[20] Because of the static head, the influx of silicone from the reservoir (which had no surface crust) advanced more rapidly than the flow front. In Figure 2, the influx is the advancing transparent region of the flow on the left of the images. The response of the flow to the compression caused by the influx depended on $\prod_{1}$. In experiments with $\prod_{1}=0$, the flow thickened near the gate, while in those with $\prod_{1}=$ 0.06 the growth of surface ridges was observed. Compressional ridges were also seen in all thin (Figures $2 \mathrm{~b}-2 \mathrm{~d}$ ) and some intermediate crust experiments but not in thick crust experiments. Marginal shear zone fractures and flow front lobes developed in intermediate and thick crust models (Figure 2f).

[21] Increasing the slope $\prod_{3}$ tended to lower the $\Pi_{1}$ values at which structures appeared. For example, experiments with "thin" $\prod_{1}$ values conducted at high $\prod_{3}$ sometimes produced shear zone fractures and flow front lobes, which are classed as "intermediate" structures. We now consider in detail the structures observed in the different classes of crustal thickness.

\subsection{No/Very Thin Crust Experiments, $\prod_{1} \leq \mathbf{0 . 1}$} $\left(\prod_{1}=0,0.06\right)$

[22] For $\prod_{1}=0$, the silicone surface remained smooth throughout an experiment. Initial extension at the flow front caused thinning of the flow, but no surface discontinuities developed. At the head of the channel, the silicone influx induced a compressional stress, hence, a shortening strain, which resulted in flow thickening. The seam between the initial flow and the reservoir silicone developed a curved cross-channel aspect with time but gradually became indistinct.

[23] For $\prod_{1}=0.06$, shortening at the channel head was initially accommodated by irregular "ripple" structures that later developed into laterally continuous, regularly spaced transverse ridges. These were deformed by the cross-channel velocity profile to become curved in plan view. Over time, 

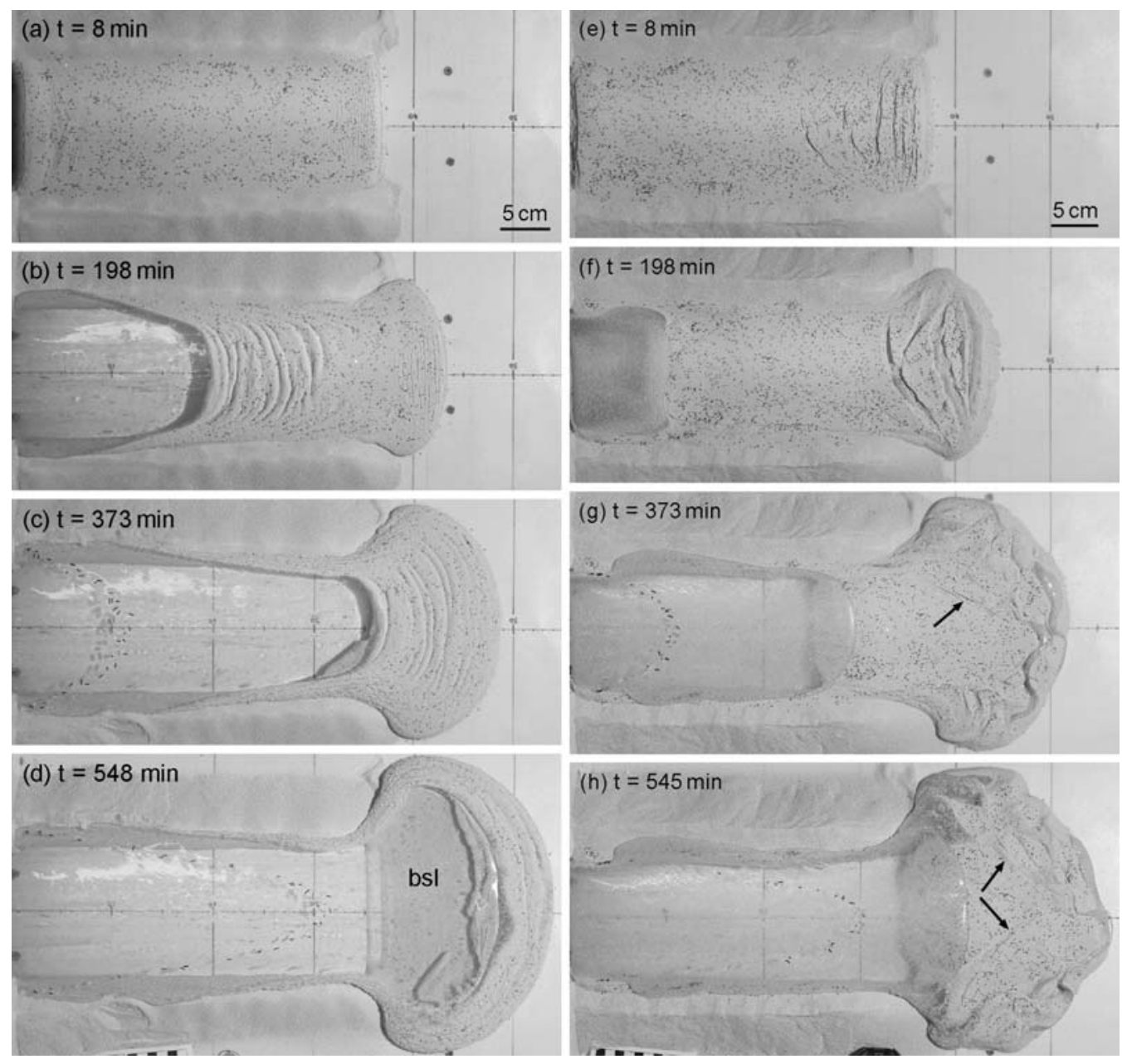

Figure 2. Image sequence illustrating the development of $(\mathrm{a}-\mathrm{d})$ a thin crust flow (experiment $19: \prod_{1}=$ $0.17)$ and $(\mathrm{e}-\mathrm{h})$ a thick crust flow (experiment $\left.20: \prod_{1}=0.5\right)$. The reservoir is beyond the left-hand side of the images. Early fracturing near the flow front as shown in Figures $2 \mathrm{a}$ and 2e was more pronounced in thick crusts, in which it was later exploited by upwelling silicone as shown in Figure $2 \mathrm{f}$. The advance of the reservoir silicone down the channel resulted in the development of compressional ridges in the thin crust as shown in Figures 2b-2d but did not deform the trailing edge of the thick crust as shown in Figures $2 \mathrm{f}$ and $2 \mathrm{~g}$. Late-stage compression, as the reservoir silicone advanced on the flow front, deformed the upwelled silicone ridges in the thick crust as shown in Figures $2 \mathrm{~g}$ and $2 \mathrm{f}$. Widespread fracturing occurred in both cases but was most obvious in the thick crust (arrows, Figures $2 g-2 h$ ). Markers on the silicone (Figures 2c, 2d, 2g and $2 \mathrm{~h}$ ) illustrate the smoothly curved cross-channel velocity profile typical of Newtonian fluids. "Caterpillar track" motion produced a basal sand layer (bsl in Figure 2d).

the ridges extended downflow, due both to the growth of new structures and the transport of existing structures as the flow advanced. They eventually reached the flow front (Figure 2d).

[24] The flow front outline remained smooth throughout all experiments. For $\prod_{1}=0.06$, the core was never exposed through the crust. Cutting a section through the front of this experiment revealed a simple vertical structure (Figure 4).

3.2. Thin Crust Experiments, $0.1<\prod_{1} \leq 0.2\left(\prod_{1}=0.17\right)$

[25] The initial extension of the flow front caused fine, closely spaced tensile fractures to open, which widened with time. The fracture field propagated upflow, where spacing increased slightly, while fracture length decreased, giving the fracture field a curved outline (Figure 5). Later, lateral spreading beyond the levées generated new tensile fractures that broke the strips of crust between the original tensile fractures into equant crustal "plates": fracture-bounded elements of crust that appeared to behave rigidly.

[26] Compressional ridges again developed ahead of the silicone influx at the channel head. Their greater spacing and amplitude meant that the transition from irregular ripples to regular ridges was clearer than for $\prod_{1}=0.06$ (Figure 5 and Table 4). In cross section, the ridges had smooth, open crests and sharp, cuspate troughs.

[27] As the silicone influx approached the flow front, the prevailing stresses in the crust became everywhere compressive, causing the rearmost tensile fractures to close. 


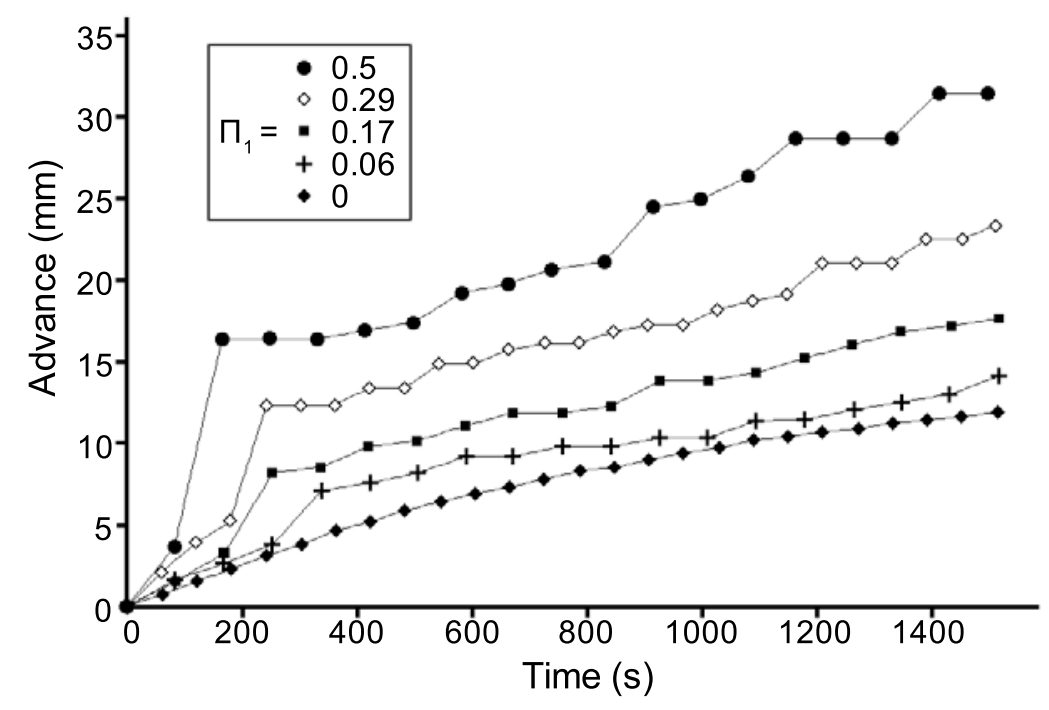

Figure 3. Plot showing the advance of experimental flows from all crustal thickness classes, over the first 25 min. No crust, experiment 25: $\prod_{1}=0$. Very thin crust, experiment $24: \prod_{1}=0.06$. Thin crust, experiment 19: $\prod_{1}=0.17$. Intermediate crust, experiment $17: \prod_{1}=0.29$. Thick crust, experiment $20: \prod_{1}=0.5 . \prod_{3}$ is $4^{\circ}$ in all cases. Advance rates increase with $\prod_{1}$. In the absence of crust, the rate of advance slows gradually with time following the initial sagging of the front. When crust is present, a sharp step in the advance shortly after the beginning of the experiment indicates some avalanching of the crust from the flow front. The quantity of crust, hence, the size of the step, increases with $\prod_{1}$. A greater quantity of avalanched crust also causes increasingly episodic flow advance.

Lateral spreading and downslope shortening produced a fine network of cross-hatching fractures over the whole crust. Again, the flow front outline remained smooth throughout the experiments.

\subsection{Intermediate Crust Experiments, $0.2<\prod_{1} \leq \mathbf{0 . 3}$ $\left(\prod_{1}=\mathbf{0 . 2 9}\right)$}

[28] With increasing $\prod_{1}$, the tensile flow front fractures developed more rapidly, and their spacing, width, and curvature generally increased (Figure 6a and Table 4). Curvature also increased upflow from the front. Compressional ridges, which did not develop in all experiments, had longer wavelengths (Table 4) and were more irregular than for lower $\prod_{1}$

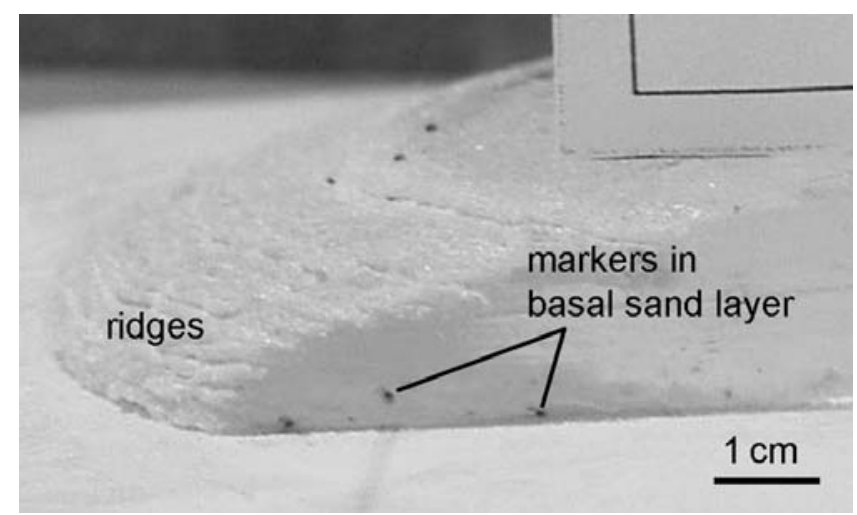

Figure 4. Cross section through the front of a very thin crust flow (experiment $24: \prod_{1}=0.06$ ). The vertical structure is simple, with no mixing between crust and core. Rolled over surface markers are visible in the basal sand layer.
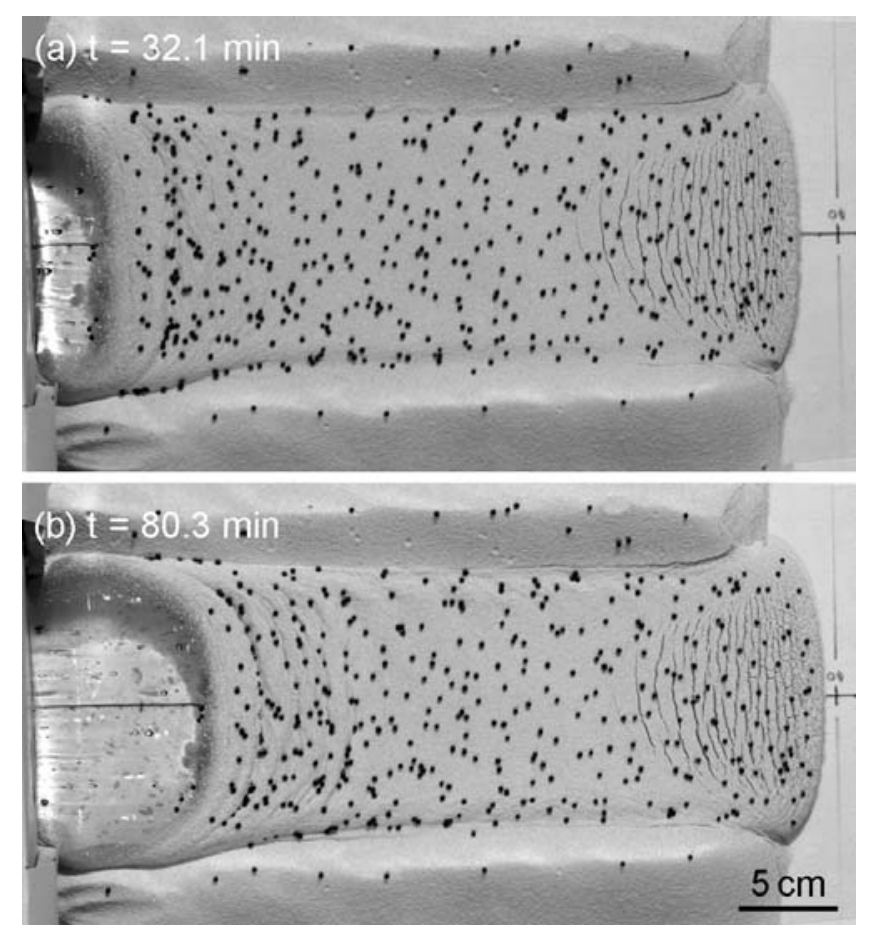

Figure 5. Crustal deformation during the early stages of a thin crust flow (experiment $34: \prod_{1}=0.17$ ). (a) A region of narrow tensile fractures developed behind the flow front. As the silicone from the reservoir entered the channel, the crust ahead was compressed, resulting in irregular ripple structures. (b) Fifty minutes later, more regular wavelength surface ridges were discernable. These had smooth, open crests and sharp, cuspate troughs. 
Table 4. Average Dimensions of the Structures Developed for Each Crustal Thickness Used ${ }^{\text {a }}$

\begin{tabular}{lccc}
\hline Crust Thickness $\left(\prod_{1}\right)$ & Maximum Tensile Fracture Spacing $(\mathrm{cm})$ & Tensile Fracture Zone Length $(\mathrm{cm})$ & Fold Wavelength $(\mathrm{cm})$ \\
\hline very thin $(0.06)$ & - & - & 0.43 \\
thin $(0.17)$ & 0.97 & 9.50 & 1.19 \\
intermediate $(0.29)$ & 1.39 & 10.71 & 2.37 \\
thick $(0.38)$ & 2.69 & 12.60 & - \\
thick $(0.44)$ & 3.99 & 17.77 & - \\
thick $(0.5)$ & 3.56 & 15.19 & - \\
\hline
\end{tabular}

\footnotetext{
${ }^{a}$ No structures were observed for $\prod_{1}=0$. Tensile fracture spacing is the average of the maximum spacing (measured down the centerline of the channel) for each experiment. Tensile fracture zone length was measured down the channel centerline. As $\prod_{1}$ increased, fracture spacing, fracture zone length, and fold wavelength generally increased. The values for $\prod_{1}=0.5$ do not fit the trend, which may be due to lack of data: only 2 experiments were conducted with this crustal thickness. Fold amplitude increased with wavelength, being of similar order.
}

(Figure 6a). The later generation of cross-hatched fractures that developed under compression were more widely spaced and broke the crust into plates. The intersection angle of the fractures was $60^{\circ}$, identifying them as conjugate sets of shear fractures.

[29] Two significant structural differences were observed between thin and intermediate crust experiments. First, brittle failure of the crust produced oblique, en echelon, synthetic shear fractures down the channel margins in all intermediate crust experiments but only in two thin crust examples. The fractures were $\sim 3 \mathrm{~cm}$ long and oriented at $\sim 15^{\circ}$ to the levées (Figure 6a). Second, flow front lobes developed in the intermediate crust experiments (Figure 6b), the sizes and positions of which reflected the distribution of crustal plates.

\subsection{Thick Crust Experiments, $\prod_{1}>0.3\left(\prod_{1}=0.38\right.$, 0.44, 0.5)}

[30] The tensile flow front fractures were very widely spaced (Table 4) and had a horst and graben structure at higher $\prod_{1}$ values. Fracture curvature again increased upflow. Opening of the arcuate rearmost fractures was not instantaneous but began at the channel center and progressed symmetrically to the margins, so that the fractures narrowed toward the margins (Figure 7). Isostatic upwelling of the core was observed as the tensile fractures widened. No compressional ridges formed at the channel head, and the silicone influx was not observed in front of the gate as soon after the start of an experiment as for lower $\prod_{1}$ values. Doming of the crust occurred close to the gate during the early part of the experiments.

[31] Although oblique fractures developed initially in the shear zones, these were longer and more widely spaced than in intermediate crusts (Figure 8). With time, the fractures grew lower-angle extensions then merged to form single, sinuous fractures down each margin that diverged slightly downflow. Once the fractures merged, the velocity of the central part of the crust increased sharply.

[32] As the silicone influx advanced down the channel, the rearmost tensile fractures narrowed but could not close because of the upwelled silicone core. Compression and deformation of the upwelled silicone produced complex flow surface morphologies (Figure 9). Conjugate fracture spacing increased with $\prod_{1}$, and only one orientation developed on either side of the flow centerline. The resultant arrowheadshaped crustal slab (Figure 9) advanced more rapidly than the frontal and lateral portions of the flow, "bulldozing" outlying crustal plates toward the margins where they were tilted toward the flow front, causing flow thickening. The slab
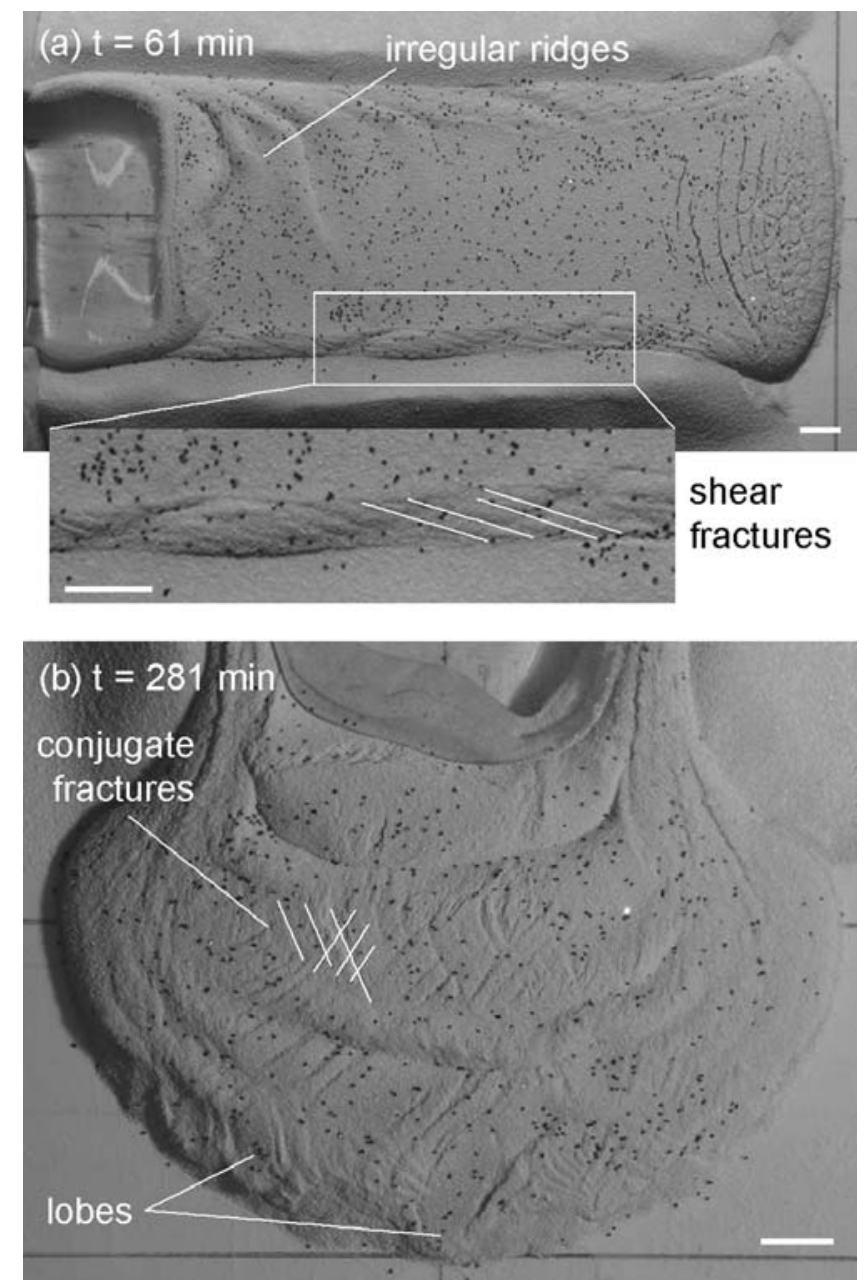

Figure 6. Ridge and fracture morphology in an intermediate crust flow (experiment 16: $\prod_{1}=0.29$ ). Scale bars are $2 \mathrm{~cm}$. (a) Where ridges developed in intermediate crusts, they had longer wavelengths and were more irregularly shaped than in thin crusts. They commonly extended further down the marginal shear zones than in the channel center. Short, synthetic shear fractures, oriented at $\sim 15^{\circ}$ to the levées, were ubiquitous in intermediate crusts. (b) Conjugate shear fractures developed under compression, creating crustal plates that influenced the advance of the flow front, causing the development of small lobe structures. 


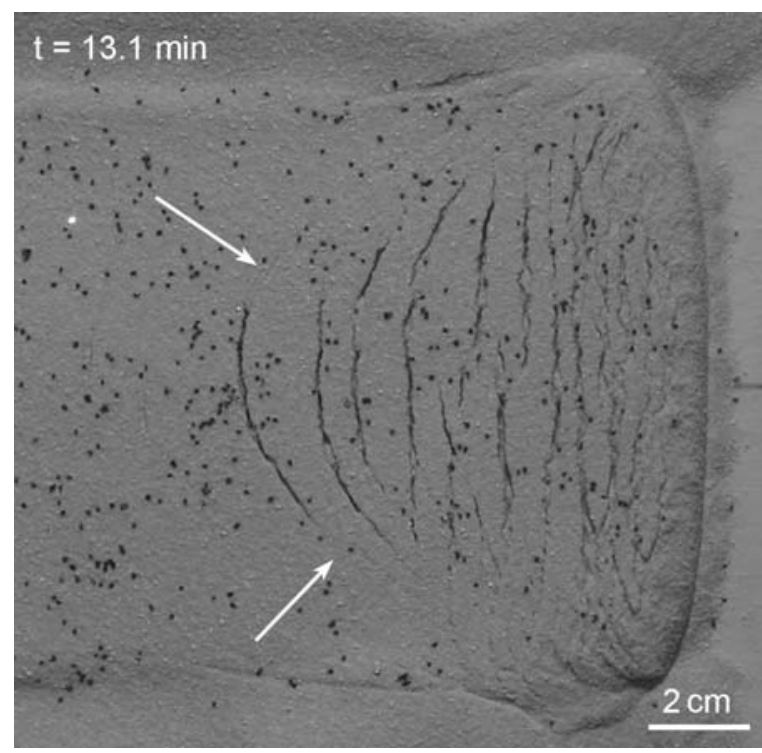

Figure 7. Arcuate tensile fractures in a thick crust experiment (experiment 14: $\prod_{1}=0.38$ ). Fracture curvature has increased with $\prod_{1}$, as can be seen by comparison with Figures 5 and 6 . The rearmost fracture is wider in the center of the channel, where it opened first. The fainter extensions (arrowed) indicate that the fracture was "unzipping" toward the margins. Some collapse of sand into the fractures was observed.

eventually broke into smaller plates as progressive generations of conjugate fractures developed.

[33] Thick crust flow fronts were strongly lobate, with lobe size and position again reflecting crustal plate distribution, hence, conjugate fracture spacing. Removing the crust after an experiment revealed layers of silicone interleaved with plates of crustal material (Figure 10). Comparing Figures 10 and 4 shows a clear increase in the internal complexity with $\prod_{1}$.

\section{Discussion}

\subsection{Experimental Flow Features}

[34] The different structures that developed within an experimental flow reflected the spatially varying stress-

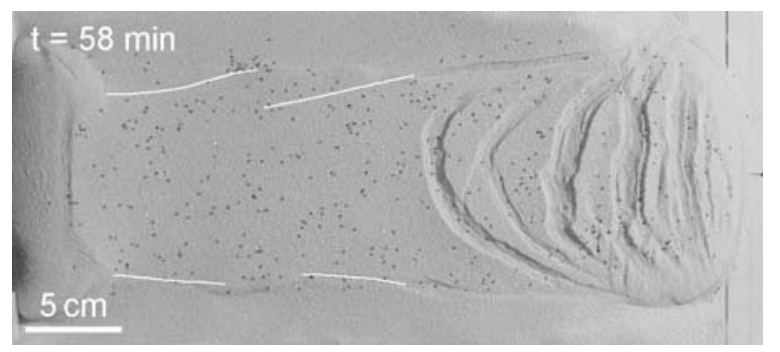

Figure 8. Shear zone fracture morphology in the early stages of a thick crust experiment (experiment 6: $\prod_{1}=$ 0.44). Oblique shear fractures developed on both sides of the channel but were longer and more widely spaced than in intermediate crusts (Figure 6a). These fractures were transient, rapidly linking to form a single sinuous fracture down each margin.

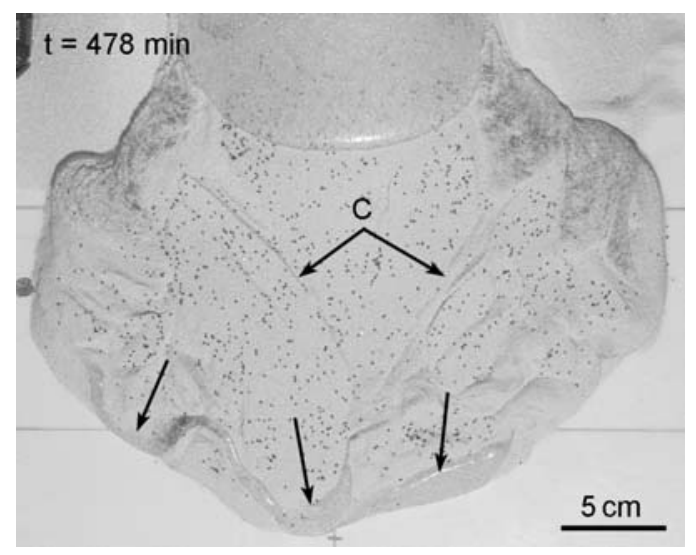

Figure 9. Complex morphology in a thick crust flow front (experiment 20 : $\prod_{1}=0.5$ ). Widely spaced conjugate fractures ("c") are seen, though only one orientation grew on either side of the centerline of the channel. Arrows indicate the ridges of silicone that welled up through the initial tensile fractures and were then deformed by the action of the surrounding crustal plates.

strain distribution. Structural variation between experiments indicates the dependence of the stress-strain distribution on $\Pi_{1}$ and, to a lesser extent, $\prod_{3}$. Increasing $\prod_{1}$ increased crustal strength, while increasing $\prod_{3}$ tended to increase the importance of gravitational effects, at the expense of crustal strength, in controlling morphology [Gregg and Fink, 2000].

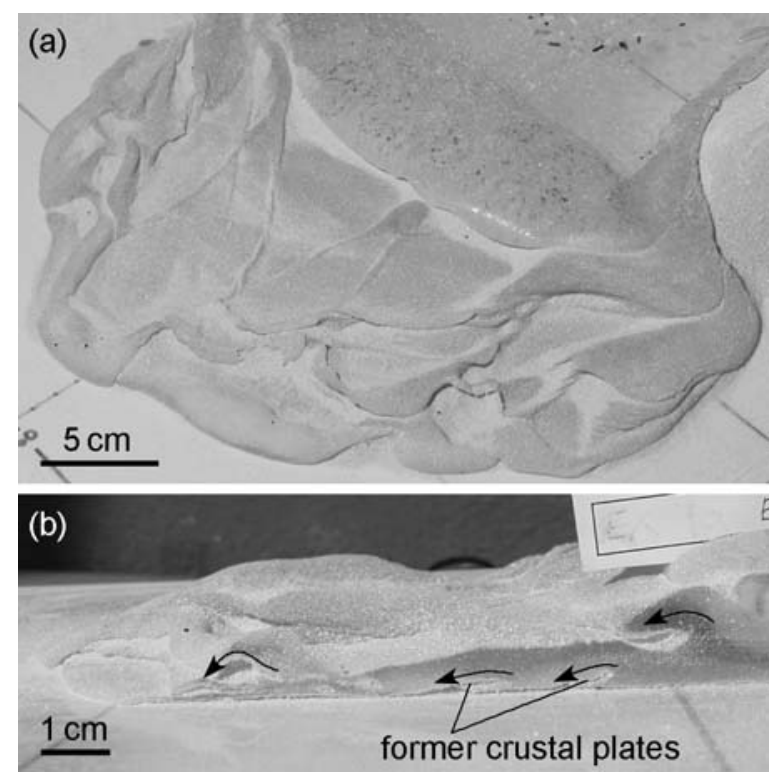

Figure 10. Core structures in thick crust flows. (a) Following crust removal, the flow front was seen to consist of layers of silicone interleaved with pockets of sand, representing progressive generations of upwelled silicone ridges that were deformed to trap crust plates between them (experiment 20: $\prod_{1}=0.5$ ). (b) Section through a flow front (experiment 22: $\left.\prod_{1}=0.44\right)$. Deformation of upwelled silicone ridges in the direction of flow is indicated by the arrows. Sand-filled cracks at the base of the flow are remnants of early crustal plates. 
(a)

(b)
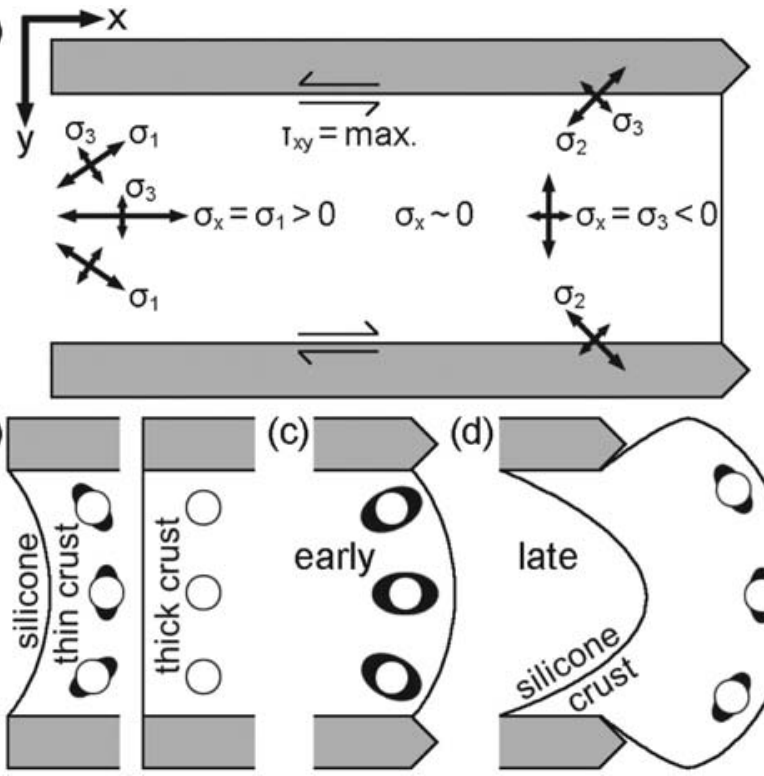

(d)

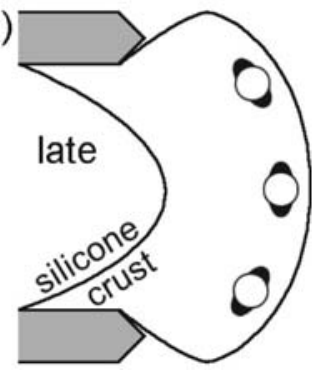

Figure 11. Sketch showing stress and strain regimes in the experimental flows. (a) Frame of reference used when referring to stress directions. $\sigma_{x}$ is the down-channel normal stress, and $\tau_{x y}$ is the wall shear stress. Initially, $\sigma_{x}$ is everywhere low. As the front extends, $\sigma_{x}$ becomes negative $\left(\sigma_{3}\right)$. At the head of the channel, the silicone influx causes $\sigma_{x}$ to become positive $\left(\sigma_{1}\right)$. In the medial channel, $\sigma_{x}$ remains close to zero for longer. $\sigma_{1}$ is the maximum, $\sigma_{2}$ is the intermediate, and $\sigma_{3}$ the minimum principal stress, the directions of which are modified by the shear stresses close to the margins. After the studies of Nye [1952] and Schreurs et al. [2006]. (b) Initial strain distributions near the head of the channel in thin and thick crusts. Thin crusts experience longitudinal compression, while thick crusts are not deformed. (c and d) Strain distributions near the flow front, which are largely independent of $\Pi_{1}$. (c) Initially, early spreading causes extension and frontal thinning. (d) Later, the advance of the silicone influx causes compression, downflow shortening, and frontal thickening.

That slope did not prove a more significant control on morphology in our experiments may be due to the relatively low values used. Gregg and Fink [1995] used slopes of $0^{\circ}$ to $60^{\circ}$, finding that the effects of slope were only detectable above $10^{\circ}$.

[35] Stress at the flow surface can be described using a coordinate system in which $x$ is the downflow, and $y$ is the cross flow, direction. Figure 11a shows the initial stress regime, while Figures $11 \mathrm{~b}, 11 \mathrm{c}$, and $11 \mathrm{~d}$ show the resultant strains at different stages, as interpreted from the surface structures. The longitudinal normal stress $\sigma_{x}$ varied in magnitude along the channel and could be compressive, tensile, or zero. Under compression, $\sigma_{x}=\sigma_{1}$, the maximum principal stress. Under tension, $\sigma_{x}=\sigma_{3}$, the minimum principal stress. Initially, $\sigma_{x}$ was everywhere close to zero. The initial opening of fractures near the flow front indicates that $\sigma_{x}$ rapidly became tensile $\left(\sigma_{3}\right)$ near the flow surface in this region (Figures 11a and 11c). At the head of the channel, the silicone influx caused $\sigma_{x}$ to become compressive $\left(\sigma_{1}\right)$ (Figure 11b). Between these zones, $\sigma_{x}$ remained low for longer, but as the influx approached the flow front, compression was

experienced everywhere, and the entire crust was deformed (Figure 11d).

[36] Surface velocity contour maps have been produced from the results of the surface marker tracking and can be

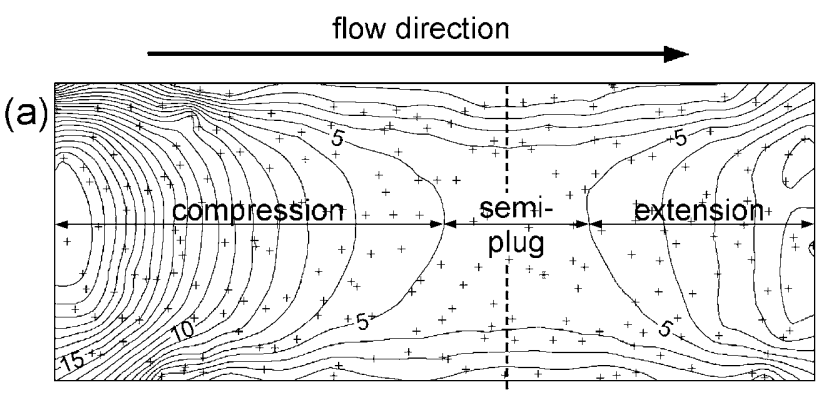

(b)

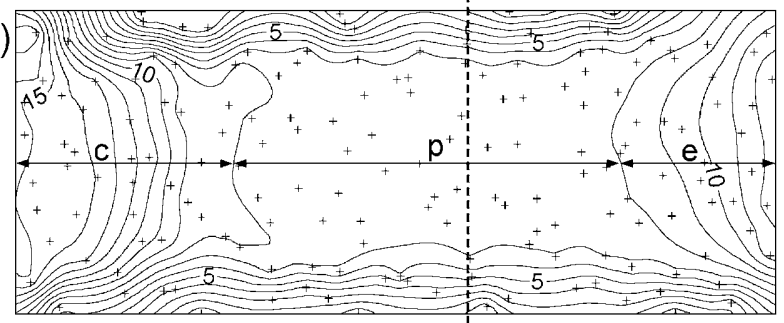

(c)

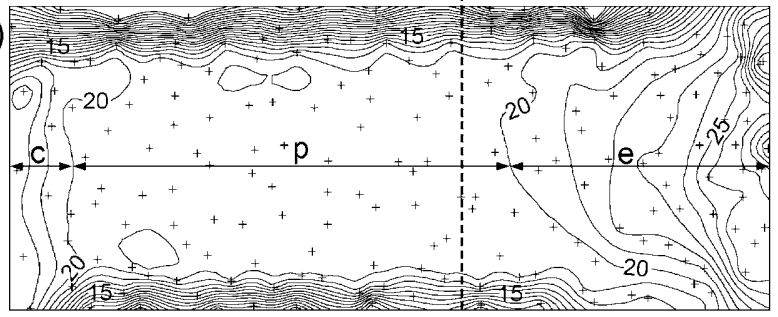

(d)

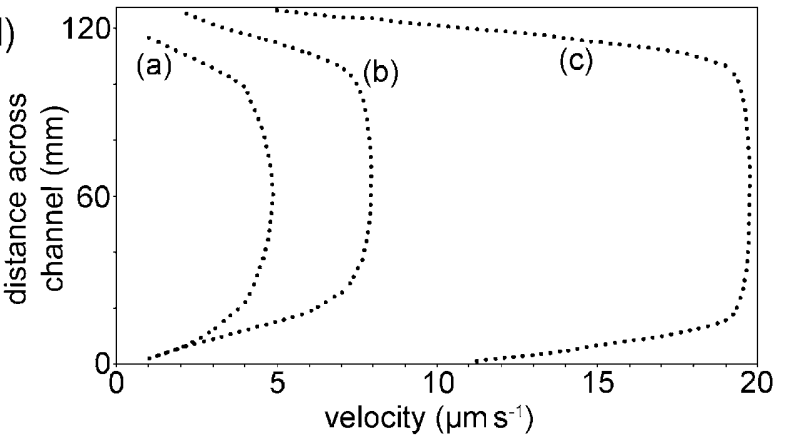

Figure 12. Velocity plots for the time interval $\sim 7-12 \mathrm{~min}$ after the start of three experiments. Crosses indicate data points, and the data have been interpolated and contoured. (a) Very thin crust (experiment $24: \prod_{1}=0.06$ ). (b) Intermediate crust (experiment 21: $\prod_{1}=0.29$ ). (c) Thick crust (experiment 23: $\prod_{1}=0.38$ ). Contour spacing is $1 \mu \mathrm{m} \mathrm{s}^{-1}$. Regions of extension (flow front), compression (channel head), and shear (channel margins) are identifiable from the pattern of contours. With increasing $\prod_{1}$, the compressional region decreased in size, and the plug (p), the contour-free area in the medial channel, increased in size. Flattened contours near the channel head reflect plug flow in higher $\prod_{1}$ experiments. The shape of the contours in the tensile region (e) did not change significantly with $\prod_{1}$. (d) Cross-channel velocity profiles, measured across the transect indicated by the dashed line, show increasing plug velocities and steeper velocity gradients in the shear zones with increasing $\prod_{1}$. 


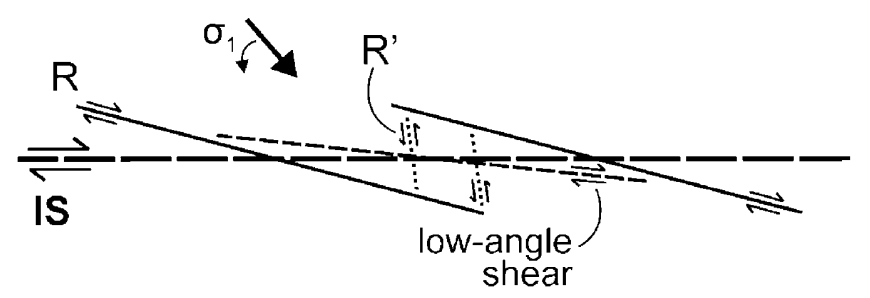

Figure 13. Possible fracture orientations in a zone of simple shear, corresponding the right-hand margin of one of our experimental channels. IS represents the direction of imposed shear. Initially, $\sigma_{1}$ is oriented at $45^{\circ}$ to IS [Mandl et al., 1977], causing synthetic $\mathrm{R}$ shears to form, making angles of $\sim 15^{\circ}$ with IS. Conjugate, antithetic, $\mathrm{R}^{\prime}$ shears may also form, though these cannot accommodate large strains and were not seen in our models. Following $\mathrm{R}$ shear formation, $\sigma_{1}$ may locally rotate (as indicated), causing low-angle shears to develop. R shears were seen in intermediate and thick crust experiments (Figures $6 \mathrm{a}$ and 8). In thick crusts, these were later linked by low-angle shears to produce an initially sinuous, through-going strike-slip fault. After the study of Naylor et al. [1986].

used to illustrate the strain experienced by the experimental crusts (Figure 12). Closely spaced contours (steep velocity gradients) are indicative of regions of high strains and strain rates that are likely to be strongly deformed. Flow front extension is evidenced by velocities that decrease upflow, while compression at the channel head is reflected in velocities that decrease downflow. As $\prod_{1}$ increased, contours in the compressional region became flattened, and this region decreased in size; lateral velocity gradients steepened, and shear zones generally narrowed. Contour shape in the tensile region remained largely unaffected. A surface "plug" was observed for all $\prod_{1}$ : a medial portion of the crust that experienced low cross-channel velocity gradients. The plug experienced negligible strain, implying that $\sigma_{x}$ was below the yield strength of the crust in this region, and deformation was localized at its front and rear. Plug size increased with $\prod_{1}$, reflecting increasing crustal strength, and plug velocity also increased (Figure 12d).

[37] We now consider the development of each type of structure (fractures, ridges, and lobes) individually, before discussing the overall crustal deformation and flow behavior.

\subsubsection{Fractures}

[38] Fractures developed in all but the no/very thin crust experiments, and their morphology varied systematically with $\prod_{1}$. The spacing and curvature of tensile fractures and the length of the fracture zone increased with increasing $\prod_{1}$ (Table 4). The size of the fracture zone depended on the magnitude of the tensile strain near the flow front. Because the force acting to drive the flow downslope increased with $\prod_{1}$ (and also $\prod_{3}$ ), thicker flows (and those on steeper slopes) experienced greater tensile stresses at the flow front, hence, greater strains. Consequently, a longer section of the channel was affected by fracturing.

[39] The curvature of tensile fractures in the presence of wall shear stresses, which was also observed by Lescinsky and Merle [2005] and Schreurs et al. [2006], may reflect the varying influence of the normal and shear stresses across the channel (Figure 11a). The $\sigma_{3}$ direction rotates from flow parallel at the channel center to oblique near the margins, so fractures opened transverse to flow direction at the center but curved downslope toward the margins. In thick crusts, the tensile fractures initiated at the channel center and "unzipped" toward the margins (Figure 7). Initiation of crustal failure at the channel center reflected the cross-channel velocity profile, which caused the maximum down-channel stress, strain, and strain rate to be experienced here in the accelerating flows.

[40] Similar modeling approaches designed to study extrusion tectonics and back arc spreading in subduction zone settings have generated similar, though not identical, fracture distributions [e.g., Hatzfeld et al., 1997; Gautier et al., 1999; Schellart and Lister, 2005]. In this work, brittle-viscous models were allowed to spread through a constriction. Although transverse tensile fractures opened near the spreading front, deformation was dominated by conjugate sets of strike-slip (transtensional) fractures [e.g., Figure 6, Hatzfeld et al., 1997], which intersected at $45^{\circ}-70^{\circ}$, measured transverse to spreading [Gautier et al., 1999]. Increasing the brittle layer thickness concentrated deformation on a smaller number of normal fault-bounded grabens [Schellart and Lister, 2005; Figure 6]. Although the sense of movement on our arcuate fractures was transtensional near the flow margins, conjugate fracturing was not the dominant morphology in our tensile zones, possibly because of the differing experimental setup. While our flows spread from a confining channel, the tectonic models spread through a constriction, behind which material flowed laterally into the tensile zone, producing a different stress-strain distribution.

[41] During the later stages of our experiments, the advance of the silicone influx meant downflow compression was experienced throughout the crust (Figure 11d). The resulting conjugate shear fractures intersected at $\sim 60^{\circ}$, which corresponds to the Mohr-Coulomb failure direction in a compressive stress regime. This is $\pm\left(45^{\circ}-\varphi / 2\right)$ to the direction of $\sigma_{1}$ (downflow), where $\varphi$, the angle of internal friction, is $\sim 30^{\circ}$ for the sand and plaster mix. Gautier et al. [1999] measured similar intersection angles for their conjugate transtensional fractures but transverse to spreading direction, indicating that in their experiments, $\sigma_{1}$ was oriented crossflow. During the early, tensile phase of our experiments, $\sigma_{1}$ was vertical near the front, with $\sigma_{2}$ cross-flow in the plane of the flow surface (Figure 11a). This difference, which is attributable to the lateral flow of material in the tectonic models, accounts for the slightly different tensile fracture patterns observed.

[42] Brittle deformation in the shear zones of intermediate and thick crust experiments was morphologically comparable to fault patterns observed during basement-controlled wrench faulting experiments [e.g., Riedel, 1929; Tchalenko, 1970; Naylor et al., 1986]. Synthetic fractures initially developed at $\sim 15^{\circ}$ to the levées. If the shear zones are modeled as simple shear systems, with $\sigma_{1}$ oriented at $\sim 45^{\circ}$ to the direction of imposed shear [Mandl et al., 1977], the fractures correspond to one of the two Mohr-Coulomb failure directions (Figure 13). These are Riedel (R) shears, which were observed by Naylor et al. [1986] to increase in length as the brittle layer thickness increased, consistent with our observations. Antithetic, anti-Riedel ( $\left.\mathrm{R}^{\prime}\right)$ shears, which correspond to the other failure direction, may develop, but are unfavorably oriented to accommodate large displacements, 


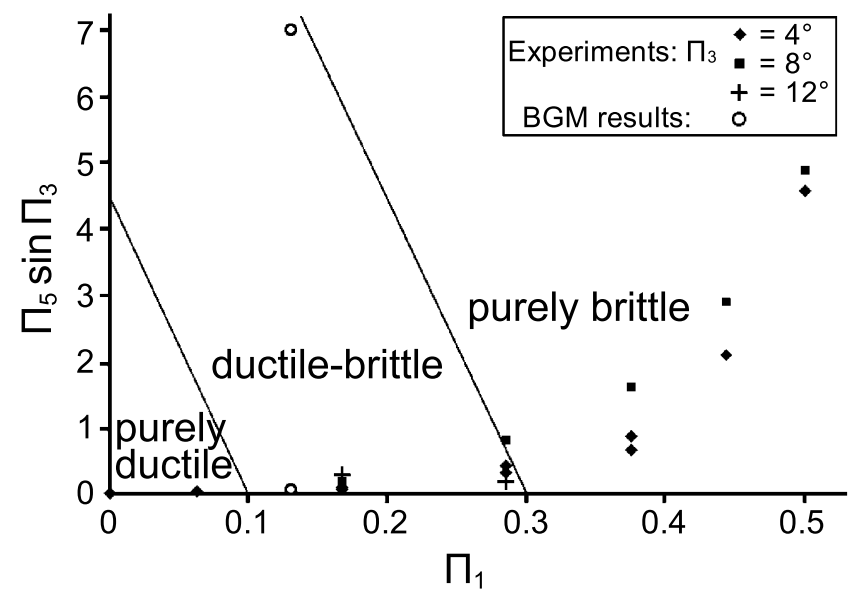

Figure 14. The relationship between $\prod_{1}$, the ratio of crustal to total flow thickness and $\prod_{5} \sin \prod_{3}$, an expression for the relative influence of the brittle crust and the viscous flow core. Increasing $\prod_{1}$ caused a rapid increase in $\prod_{5} \sin \prod_{3}$, demonstrating the increasing influence of the brittle crust on flow behavior. The results are divided into those which showed only ductile, those that showed both ductile and brittle, and those that showed only brittle deformation. The structures that developed depended strongly on $\prod_{1}$ but also weakly on slope $\prod_{3}$, which hastened the onset of brittle deformation. The open circles indicate the results of the analysis of the Big Glass Mountain (BGM) rhyolitic obsidian, which falls in the brittle-ductile regime.

so are short lived [Naylor et al., 1986]. They were not observed in our models. With increasing $\prod_{1}$, the $\mathrm{R}$ shears in our experiments merged through the growth of low-angle extensions, and fault lenses occasionally developed. This may be explained by local modification of the original stress field. Between the $\mathrm{R}$ shears, $\sigma_{1}$ rotates to become more closely parallel to the direction of imposed shear, producing new, lower-angle fractures [e.g., Naylor et al., 1986; Schellart and Nieuwland, 2003] (Figure 13). The low-angle faults, which are more favorable for accommodating displacement, gradually replace $\mathrm{R}$ shears, and the merging of initial faults produces a through-going strike-slip fault that may incorporate fault lenses. The through-going fractures in our thick crust experiments were initially sinuous, reflecting their origin as several individual fractures.

\subsubsection{Ridges}

[43] Compressional ridges developed in very thin, thin, and some intermediate crust experiments. A folding model has been used successfully to describe surface ridges on pāhoehoe [Fink and Fletcher, 1978] and on dacitic and obsidian [Fink, 1980a] lava flows. Because there are other mechanisms by which surface structures resembling folds can arise, ridge development must be examined before being attributed to folding.

[44] Folding is inferred to result from the horizontal shortening of a medium in which a vertical velocity gradient exists [Fink and Fletcher, 1978]. We observed that although shortening and thickening occurred in experiments with no crust, ridges only formed when crusts were present. Fink and Fletcher [1978] suggested that shortening causes small surface perturbations that are selectively amplified according to wavelength and that mature folds are dominated by a single wavelength that increases with the thickness of the high viscosity boundary layer. We observed a similar trend in the experiments, in which irregular ripple structures preceded the development of regular ridges. Our unpublished calculations support the theory that folding is an appropriate mechanism to invoke for compressional ridge formation in our models.

\subsubsection{Lobe Formation and Internal Structure}

[45] The morphology of the flow front lobes that formed in intermediate and thick crust experiments depended on the conjugate fracture spacing. Conjugate fracturing caused heterogeneous crustal distribution, resulting in uneven loading of the core by crustal plates, and the uneven avalanching of material from the flow front. Crustal plates pushed regions of the flow front outwards, leaving embayments in the front aligned with the fractures, which accounts for the relationship between fracture spacing and lobe size. The absence of lobes in very thin and thin crust experiments suggests that the weight of crust was insufficient to deform the core significantly. Material avalanching from the front slowed flow front advance unevenly, contributing to lobe formation when in sufficient quantities.

[46] The internal complexity of flow fronts increased markedly with $\prod_{1}$ (compare Figures 4 and 10). Late-stage compression rolled the silicone upwelled through the tensile fractures forward, entraining pockets of crustal material and resulting in a layered structure (Figure 10). Early examples of this process were preserved at the flow base as small, sandfilled cracks. The comparatively simple structure of experiments with $\prod_{1}<0.3$ is explained by the absence of upwelling. 4.1.4. Localization of Deformation: Brittle Versus Ductile Structures

[47] As $\prod_{1}$ increased, the change in structures reflected a transition in crustal response from ductile deformation (folds only) through brittle-ductile (folds and fractures) to purely brittle failure (fractures only). In most cases, increasing $\prod_{3}$ also hastened the onset of brittle deformation. Increasing either $\prod_{1}$ or $\prod_{3}$ increased channel velocities (the former because of increased overall flow thickness), producing steeper-cross-channel velocity gradients, higher wall shear stresses, and higher strain rates.

[48] Flow behavior can be characterized by the dimensionless parameter $\prod_{5}$, which illustrates the relative influence of the brittle and ductile layers in terms of gravitational and viscous forces. Schueller and Davy [2008] defined a similar parameter $\Gamma$ a "brittle-to-ductile strength ratio," to describe the behavior of simulated brittle-ductile lithospheric deformation under shortening.

[49] Plotting $\prod_{5} \sin \prod_{3}$ against $\prod_{1}$ shows that the influence of the brittle crust on the overall flow behavior increased as crustal thickness increased (Figure 14), as a result of greater crustal strength. The increasing strength with $\prod_{1}$ also affected the fracture distribution. At low $\prod_{1}$ (hence low $\prod_{5} \sin \prod_{3}$ ), the crust was pervasively deformed by many fractures with small offsets, but as $\prod_{1}$ increased, deformation was localized on a smaller number of larger faults. The localization of deformation with increasing brittle crustal thickness, which was also observed in the tectonic models, can be explained in terms of the distribution of strain over the fractures that developed. As $\prod_{1}$ increased, the number of fractures that opened decreased, while the total strain experienced, save initially near the flow front, probably remained largely unchanged. The proportion of total strain accommodated by 

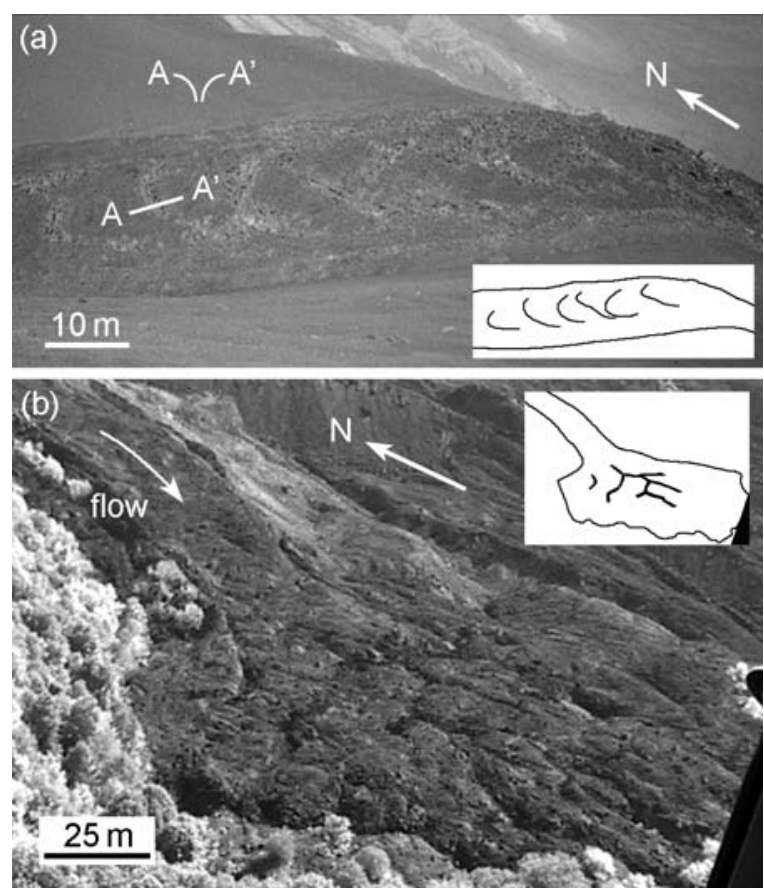

Figure 15. Structures in basaltic 'a' ā lavas that were emplaced on Mount Etna, Sicily, during July 2001. (a) Arcuate fractures in a channelized flow. As the flow approached a break in slope, the fractures developed in response to the tensile stresses experienced. The approximate cross-sectional structure of one of these fractures $\left(\mathrm{A}-\mathrm{A}^{\prime}\right)$ shows outwardly convex walls. (b) A small overflow front, which shows similar geometry to that of the experimental flows, spreading laterally beyond a channel. The flow front is lobate. The darker, approximately linear features are squeeze-ups, the distribution of which may have been controlled by conjugate shear fracture development in the crust (Image: Istituto Nazionale di Geofisica e Vulcanologia Catania).

each fracture therefore increased, resulting in wider fractures. Although no fractures were observed in the very thin crust, they may have developed but remained undetected, as they were sufficiently narrow to be rapidly infilled by shifting sand grains. Deformation, which appeared to be ductile, may not have been on a scale smaller than that usually observable.

[50] In the shear zones, strain was accommodated by $\mathrm{R}$ shears. In intermediate crusts, these survived throughout the experiment, as they were sufficiently numerous that each only experienced a small strain. In thick crusts, however, the development of low-angle shears was necessary to accommodate the greater strain experienced by the individual fractures. This facilitated the development of the throughgoing strike slip faults.

\subsection{Natural Flow Morphologies}

[51] All of the surface structures produced in the experiments have been observed on lavas and glaciers in the field. Examples are presented below, but the comparisons are largely qualitative because robust measurements of the physical properties of lavas are scarce. Measuring lava flow depths during activity and crustal depths either during or after activity is also difficult. We hope that future field work may provide data that will test our results further but suggest that the qualitative similarity demonstrated below indicates that the experiments are representative of natural flow processes.

\subsubsection{Lavas}

[52] On Etna, arcuate fractures are common on lava flows from ephemeral boccas [Kilburn, 1990] and have also been observed on large channelized 'a'à flows. Figure 15a shows an example in which arcuate fractures developed at the surface of a flow as it approached a break in slope, so experienced tensile stresses. These fractures have outwardly convex walls, reminiscent of crease structures observed on lava flows and domes, which are fractures through which the hot core wells up, then cools and solidifies [Anderson and Fink, 1992]. Although upwelling occurred in our experiments, true crease structures could not develop because the core could not solidify [Lescinsky and Merle, 2005].

[53] Figure 15b shows an example of suspected conjugate shear fractures on an ' $a$ ' $\mathbf{a}$ flow unit. This flow is geometrically similar to the experimental flows, spreading laterally beyond confining levées. The dark, linear surface features are "squeeze-ups" of the flow core through the crust [Applegarth et al., 2010]. Although the oblique view prevents estimation of their relative orientations, they appear to be aligned in two dominant directions. In the absence of squeeze-ups, the fractures may have remained unobserved because of the collapse of clinker into them. This may also be the reason that marginal shear fractures have not been conclusively documented on lavas.

[54] Flow front lobes are observed on lavas of all compositions (e.g., Figure 15b), but their development in clinkercovered lavas is less well understood than in pāhoehoe flows. It is unlikely that higher-silica flows develop lobes through sequential, pāhoehoe-like crustal failure, as they rarely (if ever) develop breakouts or tubes. Our experiments provide a lobe formation mechanism that does not require the viscoelastic layer reported in pāhoehoe [Hon et al., 1994], supporting the suggestion of Kilburn [1993] that brittle crusts may actively alter flow behavior rather than resting passively on the ductile flow core. The formation of lobes through the development of conjugate fractures, hence crustal plates, is invoked in the flow front development of one of the 2001 Etna lava flow fields [Applegarth et al., 2010].

[55] Folding is observed in lavas of all compositions. Using data from the study of Fink [1980a, 1980b], we estimate $\prod_{1}$ and $\prod_{5} \sin \prod_{3}$ values for the north lobe of the Big Glass Mountain rhyolitic obsidian lava flow. The flow front depth is $75 \mathrm{~m}$, and the crust depth (estimated from the maximum depth of open fractures on the flow) is $10 \mathrm{~m}$. Assuming the front is the thickest part of the flow, this gives a lower limit for $\prod_{1}$ of 0.13. Fink [1980a] states that rheological data have not been collected directly from flowing rhyolite, so estimates core viscosity from temperature measurements of a rhyodacitic eruption at Trident volcano (Alaska) $\left(900^{\circ} \mathrm{C}\right)$ [Friedman et al., 1963] and the measured water content of the Big Glass Mountain flow (0.10\%) [Shepherd, 1938]. This gives a value of $10^{8} \mathrm{~Pa} \mathrm{~s}$. The lava density is $2000 \mathrm{~kg} \mathrm{~m}^{-3}$. Depending on the time period over which the folds grew (estimated at $1 \mathrm{~h}$ to 1 week), strain rates were $1.4 \times 10^{-4}$ to $8.3 \times 10^{-7}$, which, over a distance of $500 \mathrm{~m}$, gives shortening velocities of 0.07 to $4.2 \times 10^{-4} \mathrm{~m} \mathrm{~s}^{-1}$. The flow was emplaced on a slope of $8^{\circ}$, so $\prod_{5} \sin \prod_{3}$ falls in the range $0.04-7$, suggesting that this 
flow falls in the brittle-ductile regime, which is consistent with the presence of both folds and fractures (Figure 14).

\subsubsection{Application to Glaciers}

[56] Although the experiments were designed to simulate thermally stratified lava flows, they may be relevant to the study of other flows with a rheological stratification. The power law viscous rheology of glaciers (which may also have yield strengths) can produce depth-dependent behavior that mimics rheological stratification because of stress-strain variations with depth. At depth (large stresses, low strain rates), ice deforms by ductile creep and fractures do not open. Near the surface, high strain rates promote crevasse opening by brittle fracture [Hambrey, 1976; Hambrey and Lawson, 2000].

[57] The behavior of valley glaciers was modeled by Nye [1952], who predicted the formation of arcuate crevasses under tensile stress and en echelon marginal crevasses under compressive stress. Many authors have observed such brittle deformation structures in the field, as well as ductile deformation structures including folds and crevasse traces [e.g., Hambrey and Müller, 1978; Herbst et al., 2006].

\section{Implications}

[58] Our simulations illustrate how the presence of a brittle crust may affect the advance and overall flow dynamics of a rheologically stratified flow. No surface structures developed in the absence of a crust, while the introduction of a thin crust resulted in surface folding under compression. As $\prod_{1}$ increased, the disappearance of folds and the change from smoothly curved to flattened, plug-like cross-channel velocity contours in the upper channel indicated the increasing strength of the crust in compression and shear, although the unchanging contour shape at the flow front suggests that crustal tensile strength is independent of thickness (Figure 12). The formation of lobes in intermediate and thick crusts indicated the increasing role played by the crust in modifying the flow advance as $\prod_{1}$ increased.

[59] Behavior at the crust-core interface is inferred to vary with $\prod_{1}$. At low $\prod_{1}$, crustal folding at the head of the channel was observed very soon after the start of an experiment. With increasing $\prod_{1}$, folding at the channel head was replaced by crustal doming, and the initial resistance to crust advance increased because of greater wall shear stresses. This leads us to infer some shear between the crust and core during the early stages of thick crust models, which may have led to a reverse sense of shear in the upper part of the silicone layer [Merle, 1998]. After the development of the through-going shear zone faults, the decoupling of the crustal plug from the levées would have eliminated any reverse shear.

[60] Different values of $\prod_{1}$ represent flows at different stages of emplacement. The thinnest crusts represent proximal flows that have not cooled significantly. Little or no shear is inferred between crust and core. The plug flow regime that developed with increasing $\prod_{1}$ (Figure 12) corresponds to more distal flows and may be comparable to the "mobile" crust regime described in PEG models by Griffiths et al. [2003]. Although self-supporting roofs (the "tube" regime of Griffiths et al. [2003]) did not form in our experiments because of insufficient crustal cohesion, the increasing initial resistance to crustal advance with $\prod_{1}$ suggests that the initial stages of thick crust experiments simulate conditions that are close to tube flow.

[61] Our observations indicate that as $\prod_{1}$ increased, the degree of crust-core interaction increased, and the crust played an increasingly significant role in controlling flow behavior. The core initially governed advance in all flows, shown by the curved cross-channel velocity contours (Figure 12), but the permanent disruption of thick crust fronts due to upwelling, entrainment, and avalanching affected subsequent advance. Although increased crust thickness should improve insulation, thus, reduce cooling, in lavas, our results suggest that a positive feedback mechanism may operate following thick crust fracturing. The exposure of the flow core during tensile fracturing increased with $\prod_{1}$, as fractures were wider and more upwelling occurred. In addition, more crustal material was entrained in thick crust models, which in active lavas could lead to an increased rate of cooling by advection, thus, reinforcing the tendency of the front to cease advancing. This process could be important in the cessation of cooling-limited lava flows.

[62] Dimensional analysis indicates that our experiments can represent lavas of a wide range of compositions, from basaltic 'a' $\bar{a}$ to rhyolite, so the results may assist in the interpretation of flow dynamics from surface structures on most lavas. One significant outcome concerns the advance mechanism of clinker-covered lava flow fronts beyond the channelized region, in the zone of dispersed flow [Lipman and Banks, 1987]. While lobe formation in pāhoehoe lavas has been attributed to the influence of a viscoelastic layer [Hon et al., 1994], it is less well understood in higher-silica flows. Because the tensile strength of a brittle crust is negligible in comparison with that of a viscoelastic layer, the role of the brittle layer in influencing flow behavior has often been overlooked [e.g., Iverson, 1990]. However, the development of lobes in our experiments due to fracture-related heterogeneous crustal distribution and avalanching indicates that the influence of a brittle crust on flow advance may be as significant as that of a viscoelastic layer.

[63] Despite rheological simplification, the experiments produced surface morphologies that are similar to those observed on flow of lava and ice, suggesting that a two-layer viscous-brittle rheology is capable of simulating either rheologically stratified (lava) or power law viscous (ice) rheologies. Gautier et al. [1999], who noted that their fracture patterns were similar to the slip lines produced by plane strain deformation of rigid plastics, suggest that brittle-viscous models may also simulate plastic behavior, despite none of the materials demonstrating plastic behavior.

\section{Summary}

[64] Our experimental results indicate that a brittle crust can be a significant control on the structures produced at the surface of a viscous-brittle flow, and on the flow advance mechanism, depending on its thickness. Slope was found to modify flow behavior only slightly. Increasing the ratio of crustal to total flow thickness $\left(\Pi_{1}\right)$ increases the influence of crustal strength with respect to viscous resistance (characterized by $\left.\prod_{5}\right)$. This is reflected in the development of apparently ductile structures at low $\prod_{1}$ (core control) and brittle structures at high $\prod_{1}$ (crustal control). The most sig- 
nificant outcomes of our experimental work are outlined below.

[65] 1. Increasing $\prod_{1}$ increased the localization of deformation, which at the flow front resulted in more exposure of the flow core. More crust-core interaction was observed at high $\prod_{1}$. In lavas, these processes may result in increased cooling through radiative heat loss and the entrainment of crustal material into the hot core.

[66] 2. At intermediate to high $\prod_{1}$, flow front lobes developed as a result of crustal fracturing and avalanching. We therefore question the importance of a viscoelastic layer in controlling flow advance and morphology in lavas with cohesive brittle crusts.

[67] 3. The experiments successfully reproduced surface structures observed on lavas and glaciers, providing insight into their formation. Similar features identified on flows of these rheologies in the field may be used as indicators of the flow dynamics at the time of their formation.

[68] Acknowledgments. The work was funded by Natural Environment Research Council studentship NER/S/A2005/13681 and grant NE/ F018010/1. We thank INGV Catania for providing the image used in Figure $15 \mathrm{~b}$. The manuscript was greatly improved following comments by R. Kerr, one anonymous reviewer, and the Associate Editor, W. P. Schellart.

\section{References}

Anderson, S. W., and J. H. Fink (1992), Crease structures: Indicators of emplacement rates and surface stress regimes of lava flows, Geol. Soc. Am. Bull., 104, 615-625.

Applegarth, L. J., H. Pinkerton, M. R. James, and S. Calvari (2010), Morphological complexities during the emplacement of 'a' $\bar{a}$ lava flow fields: a study of the 2001 lower flow field on Etna, Bull. Volcanol., doi:10.1007/s00445-101-0351-1.

Balmforth, N. J., R. V. Craster, A. C. Rust, and R. Sassi (2006), Viscoplastic flow over an inclined surface, J. Non-Newtonian Fluid Mech., 139 103-127.

Blake, S. (1990), Viscoplastic models of lava domes, in Lava Flows and Domes, vol. 2, edited by J. H. Fink, pp. 88-126, Springer-Verlag, New York.

Blake, S., and B. C. Bruno (2000), Modeling the emplacement of compound lava flows, Earth Planet. Sci. Lett., 184, 181-197.

Buisson, C., and O. Merle (2005), Influence of crustal thickness of dome destabilization, in Kinematics and dynamics of lava flows, edited by M. Manga and G. Ventura, pp. 181-188, Geological Society of America Special Paper 396.

Cashman, K. V., R. C. Kerr, and R. W. Griffiths (2006), A laboratory model of surface crust formation and disruption on lava flows through nonuniform channels, Bull. Volcanol., 68, 753-770.

Crisp, J., and S. Baloga (1990), A model for lava flows with 2 thermal components, J. Geophys. Res., 95, 1255-1270.

Donnadieu, F., and O. Merle (1998), Experiments on the indentation process during cryptodome intrusions: New insights into Mount St. Helens deformation, Geology, 26, 79-82.

Fink, J. H. (1980a), Surface folding and viscosity of rhyolite flows, Geology, $8,250-254$.

Fink, J. H. (1980b), Gravity instability in the Holocene Big and Little Glass Mountain rhyolitic obsidian flows, northern California, Tectonophysics, 66, 147-166.

Fink, J. H., and R. C. Fletcher (1978), Ropy pāhoehoe: Surface folding of a viscous fluid, J. Volcanol. Geotherm. Res., 4, 151-170.

Fink, J. H., and R. W. Griffiths (1990), Radial spreading of viscous gravity currents with solidifying crust, J. Fluid Mech., 221, 485-509.

Fink, J. H., and R. W. Griffiths (1992), A laboratory analogue study of the surface morphology of lava flows extruded from point and line sources, J. Volcanol. Geotherm. Res., 54, 19-32.

Friedman, I., W. Long, and R. L. Smith (1963), Viscosity and water content of rhyolite glass, J. Geophys. Res., 68, 6523-6535.

Gautier, P., J.-P. Brun, R. Moriceau, D. Sokoutis, J. Martinod, and L. Jolivet (1999), Timing, kinematics and cause of Aegean extension: A scenario based on a comparison with simple analogue experiments, Tectonophysics, $315,31-72$.
Greeley, R. (1987), The role of lava tubes in Hawai'ian volcanoes, in Volcanism in Hawai' i, edited by R. W. Decker et al., pp. 1589-1602, U.S.G.S. Professional Paper 1350.

Greeley, R., and M. B. Womer (1981), Mare Basin filling on the Moon: Laboratory simulations, Proc. Lunar Planet. Sci., 12B, 651-663.

Gregg, T. K. P., and J. H. Fink (1995), Quantification of submarine lavaflow morphology through analogue experiments, Geology, 23, 73-76.

Gregg, T. K. P., and J. H. Fink (2000), A laboratory investigation into the effects of slop on lava flow morphology, J. Volcanol. Geotherm. Res., 96, 145-159.

Griffiths, R. W., R. C. Kerr, and K. V. Cashman (2003), Patterns of solidification in channel flows with surface cooling, J. Fluid Mech., 496, 33-62.

Hallworth, M. A., H. E. Huppert, and R. S. J. Sparks (1987), A laboratory simulation of basaltic lava flows, Mod. Geol., 11, 93-107.

Hambrey, M. J. (1976), Structure of Glacier Charles-Rabots-Bre, Norway, Geol. Soc. Am. Bull., 87, 1629-1637.

Hambrey, M. J., and W. Lawson (2000), Structural styles and deformation fields in glaciers: a review, Deformation of Glacial Materials, 176, 59-83.

Hambrey, M. J., and F. Müller (1978), Structures and ice deformation in the White Glacier, Axel Heiberg Island, Northwest Territories, Canada, J. Glaciol, 20, 41-66.

Handin, J. (1966), Strength and ductility, in Handbook of physical constants, edited by S. P. J. Clarck, pp. 223-298, Geological Society of America Memoir 97.

Hatzfeld, D., J. Martinod, and G. Bastet (1997) An analogue experiment for the Aegean to describe the contribution of gravitational potential energy, J. Geophys. Res., 102, 649-659.

Herbst, P., F. Neubauer, and M. P. J. Schopfer (2006), The development of brittle structures in an alpine valley glacier: Pasterzenkees, Austria, 1887-1997, J. Glaciol., 52, 128-136.

Hess, K. U., and D. B. Dingwell (1996), Viscosities of hydrous leucogranitic melts: A non-Arrhenian model, Am. Mineral., 81, 1297-1300.

Hoek, E., P. K. Kaiser, and W. F. Bawden (1995), Support of underground excavation, in Hard Rock, edited by A. A. Balkema, Rotterdam, Netherlands.

Hon, K., J. Kauahikaua, R. Denlinger, and K. Mackay (1994), Emplacement and inflation of pāhoehoe sheet flows: Observations and measurements of active lava flows on Kilauea Volcano, Hawai'i, Geol. Soc. Am. Bull., 106, 351-370.

Hulme, G. (1974), Interpretation of lava flow morphology, Geophysical Journal of the Royal Astronomical Society, 39, 361-383.

Huppert, H. E., J. B. Shepherd, H. Sigurdsson, and R. S. J. Sparks (1982), On lava dome growth, with application to the 1979 lava extrusion of the Soufriere of St. Vincent, J. Volcanol. Geotherm. Res., 14, 199-222.

Iverson, R. M. (1990), Lava domes modeled as brittle shells that enclose pressurized magma, with application to Mount St. Helens, in Lava Flows and Domes, vol. 2, edited by J. H. Fink, pp. 47-69, Springer-Verlag, New York.

Kilburn, C. (1990), Surfaces of 'a'ā flow-fields on Mount Etna, Sicily: Morphology, rheology, crystallization and scaling phenomena, in Lava Flows and Domes, vol. 2, edited by J. H. Fink, pp. 129-156, SpringerVerlag, New York.

Kilburn, C. R. J. (1993), Lava crusts, 'a'à flow lengthening and the pāhoehoe-'a'ā transition, in Active Lavas, edited by C. R. J. Kilburn and G. Luongo, pp. 263-280, University College London, UK.

Kilburn, C. R. J. (2000), Lava flows and flow fields, in Encyclopedia of Volcanoes, edited by H. Sigurdsson et al., pp. 346-368, Academic Press, San Diego, Calif.

Kilburn, C. R. J., and R. M. C. Lopes (1988), The growth of 'a'ā lava flowfields on Mount Etna, Sicily, J. Geophys. Res., 93, 14,759-14,772.

Kilburn, C. R. J., and R. M. C. Lopes (1991), General patterns of flow field growth: 'a'ā and blocky lavas, J. Geophys. Res., 96, 19,721-19,732.

Lescinsky, D. T., and O. Merle (2005), Extensional and compressional strain in lava flows and the formation of fractures in surface crust, in Kinematics and dynamics of lava flows, edited by M. Manga and G. Ventura, pp. 163-179, Geological Society of America Special Paper 396.

Lipman, P. W., and N. G. Banks (1987), 'A'ā flow dynamics, Mauna Loa, 1984, in Volcanism in Hawai' $i$, edited by R. W. Decker et al., pp. 1527 1567, U.S.G.S. Professional Paper 1350.

Lyman, A. W., and R. C. Kerr (2006), Effect of surface solidification on the emplacement of lava flows on a slope, J. Geophys. Res., 111, B05206, doi:10.1029/2005JB004133.

Mandl, G., L. N. J. De Jong, and A. Maltha (1977), Shear zones in granular material, Rock. Mech., 9, 95-144.

Merle, O. (1998), Internal strain within lava flows from analogue modeling, J. Volcanol. Geotherm. Res., 81, 189-206.

Mourgues, R., and P. R. Cobbold (2003), Some tectonic consequences of fluid overpressures and seepage forces as demonstrated by sandbox modeling, Tectonophysics, 376(1-2), 75-97. 
Naylor, M. A., G. Mandl, and C. H. K. Sijpesteijn (1986), Fault geometries in basement-induced wrench faulting under different initial stress states, J. Struct. Geol., 8, 737-752.

Nye, J. F. (1952), The mechanics of glacier flow, J. Glaciol., 2, 82-93.

Pinkerton, H., and R. S. J. Sparks (1978), Field measurements of rheology of lava, Nature, 276, 383-385.

Riedel, W. (1929), Zur Mechanik geologischer Brucherscheinungen, Centralbl. f. Mineral. Geol. u. Pal., 1929 B, 354-368.

Rocchi, V., P. R. Sammonds, and C. R. J. Kilburn (2004), Fracturing of Etnean and Vesuvian rocks at high temperatures and low pressures, J. Volcanol. Geotherm. Res., 132, 137-157.

Schellart, W. P., and G. S. Lister (2005), The role of the East Asian active margin in widespread extensional and strike-slip deformation in Eas Asia, J. Geol. Soc. Lond., 162, 959-972.

Schellart, W. P., and D. A. Nieuwland (2003), 3D evolution of a pop-up structure above a double basement strike-slip fault: Some insights from analogue modeling, in New insights into structural interpretation and modeling, edited by D. A. Nieuwland, pp. 169-179, Geological Society London Special Publication 212.

Schreurs, G., et al. (2006), Analogue benchmarks of shortening and extension experiments, Analogue and Numerical Modeling of Crustal-Scale Processes, 253, 1-27.

Schueller, S., and P. Davy (2008), Gravity influenced brittle-ductile deformation and growth faulting in the lithosphere during collision: Results from laboratory experiments, J. Geophys. Res., 113, B12404, doi:10.1029/2007JB005560.
Shaw, H. R. (1969), Rheology of basalt in the melting range, J. Petrol., 10, $510-535$.

Shaw, H. R. (1972), Viscosities of magmatic silicate liquids: Empirical method of prediction, Am. J. Sci., 272, 870-893.

Shaw, H. R., T. L. Wright, D. L. Peck, and R. Okamura (1968), Viscosity of basaltic magma: An analysis of field measurements in Makaopuhi lava lake, Hawai'i, Am. J. Sci., 266, 225-264.

Shepherd, E. S. (1938), The gases in rocks and some related problems, Am. J. Sci., 35-A, 311-351.

Soule, S. A., and K. V. Cashman (2004), The mechanical properties of solidified polyethylene glycol 600, an analog for lava crust, J. Volcanol. Geotherm. Res., 129, 139-153.

Soule, S. A., K. V. Cashman, and J. P. Kauahikaua (2004), Examining flow emplacement through the surface morphology of three rapidly emplaced, solidified lava flows, Kilauea Volcano, Hawai'i, Bull. Volcanol., $66,1-14$.

Tanguy, J. C. (1973), The 1971 Etna eruption: petrography of the lavas, Philos. Trans. R. Soc. Lond., Ser. A, 274, 45-53.

Tchalenko, J. S. (1970), Similarities between shear zones of different magnitudes, Geol. Soc. Am. Bull., 81, 1625-1640.

L. J. Applegarth, M. R. James, and H. Pinkerton, Lancaster Environmen Center, Lancaster University, Bailrigg, Lancaster LA1 4YQ, UK. (1.j.applegarth@lancaster.ac.uk)

B. van Wyk de Vries, Laboratoire Magmas et Volcans, Université Blaise Pascal, 5 rue Kessler, 63038 Clermont-Ferrand Cedex, France. 